\title{
Rassegna bibliografica
}

La Repubblica fra società ed economia

David Forgacs, Margini d'Italia. L'esclusione sociale dall'Unità a oggi, Roma-Bari, Laterza, 2015, pp. XXVII-370, euro 26.

David Forgacs applica gli approcci e le categorie degli studi culturali e postcoloniali alla storia d'Italia e ne ricava un libro innovativo e ricco di interesse. Margini d'Italia non è una "controstoria" d'Italia vista dalla parte degli esclusi, ma un saggio che dimostra come il processo di costruzione dello Stato nazionale comporti - accanto a meccanismi di aggregazione e integrazione di spazi e gruppi — anche un moto contrario di messa ai margini e costruzione di periferie geografiche, sociali e culturali. Prende in esame cinque luoghi — uno per capitolo - a ciascuno dei quali corrisponde grosso modo anche un tempo: le periferie urbane, dall'indomani dell'Unità e con frequenti riemersioni fino agli anni del boom economico; le colonie, da fine Ottocento al periodo fascista; il Sud, con più forza nel periodo successivo alla Liberazione; i manicomi, soprattutto negli anni Sessanta e Settanta; i campi nomadi, negli ultimi trent'anni.

Il libro tratta delle rappresentazioni discorsive e visuali che furono prodotte intorno ai margini d'Italia: prende in considerazione romanzi e inchieste, la letteratura scientifica, giuridica e tecnica, e le fotografie; ogni capitolo è aperto da un ampio inserto fotografico, che è frutto della mostra Italy's Margins allestita a Roma e New York nel 2012. Ciascun capitolo è in realtà un esercizio raffinato di critica delle sue fonti; indaga la loro genesi e l'utilizzo che ne è stato fatto, discute $\mathrm{i}$ rapporti di potere che ciascuna di essa incorpora, le incrocia tra loro per evidenziarne l'implicito e svelarne il non detto. Le fotografie, osserva l'autore, quasi mai sono leggibili univocamente ma acquistano significato dall'interazione con i discorsi particolari che le hanno prodotte; esse sono una delle modalità attraverso cui si esercita un potere (lo "sguardo non corrisposto") e si costruisce un immaginario; tuttavia possono contenere anche informazioni che sfuggono alle intenzioni del fotografo e dei suoi committenti. Su questi interstizi deve lavorare lo storico per valorizzare le soggettività - latenti o tacitate - di quanti sono stati messi ai margini.

Ogni capitolo segue anche - in maniera integrata al tema affrontato - il filo del "farsi" delle scienze sociali, ovvero il progredire della riflessione sul metodo e dell'autocoscienza etica ed epistemologica di chi ha condotto ricerche sul campo e sul tempo presente. Si tratta di sociologi urbani, antropologi coloniali, etnologi, psichiatri, fotografi e giornalisti d'inchiesta: li potremmo definire cumulativamente come "intellettuali impegnati", chiamati a essere 
osservatori e spesso interpreti di mondi sociali "altri", marginali, subalterni, correndo spesso il rischio di fraintendere, di costruire stereotipi, di confermare gerarchie. Il punto più alto di questo percorso - e il modello ancora valido, secondo l'autore è quello di Ernesto de Martino, cui è dedicato il capitolo centrale del libro.

Il capitolo sulle colonie è forse il più originale per varietà di approcci e profondità di analisi. Il dossier fotografico si apre con un'istantanea scattata a Massaua nel 1935 che contiene un complesso movimento di corpi e di sguardi: al centro è una donna africana con il seno scoperto e il volto abbassato, trattenuta a forza da quattro marinai italiani che si offrono trionfanti al fotografo, e osservata da due uomini eritrei in atteggiamento compiaciuto. La linea del colore non basta a definire i confini sociali nelle colonie, se non altro perché vi si sovrappongono altre gerarchie come quelle di genere - come in questa foto - e di ceto sociale. Inoltre Forgacs dimostra che la stessa linea del colore è labile e mutevole: la percezione della "neritudine" e della "bianchezza" è cambiata nei decenni a cavallo tra Otto e Novecento, in funzione del tipo di dominio coloniale e dei soggetti che si ponevano come osservatori. Gli italiani sono proprio "bianchi"? Gli anglosassoni e i nordamericani non ne erano affatto convinti. E gli etiopi sono davvero "neri"? I loro gruppi dirigenti si sentivano discendenti da re Salomone, "semiti", e quindi migliori degli altri.

Al centro del capitolo sulle colonie vi sono le fotografie prodotte dalle inchieste etnografiche, dalle ricognizioni aeree e dalla propaganda militare. Attraverso di esse Forgacs ragiona intorno alla costruzione del "tipo" antropologico e del paesaggio coloniale come strumenti di dominio e di controllo, e riflette sull'estetizzazione della conquista e della guerra portata ai suoi massimi livelli dal fascismo e riverberata in una pletora di altre fonti, anche soggettive, come quelle dei soldati e dei piloti. Chiudono il capitolo due fotografie realizzate da patrioti etiopi durante la resistenza e dopo la liberazione del paese: questi due ritratti risaltano per contrasto rispetto alle fotografie coloniali. Inoltre Forgacs ha potuto incontrare personalmente il protagonista, che era un leader militare e politico etiope, e ricostruire con lui il contesto, le intenzioni e i codici culturali secondo cui quelle auto rappresentazioni erano state prodotte, riprendendo una riflessione che sviluppa in tutti $\mathrm{i}$ capitoli sui rapporti tra fonti visuali e fonti orali, e sull'opportunità di avvicinare e far parlare - ogni volta che è possibile i soggetti che sono stati ridotti a oggetto di discorsi e osservazioni altrui.

Alessandro Casellato

Roberto Grandinetti (a cura di), Il Friuli. Storia e società, vol. VI, 1964-2010. I processi di sviluppo economico e le trasformazioni sociali, Udine, Istituto friulano per la storia del movimento di Liberazione, 2016, pp. 565, euro 35.

Con il presente volume si conclude la monumentale collana in sei tomi edita dall'Istituto friulano per la Storia del movimento di Liberazione dedicata alla storia economica e sociale dal 1797 ai giorni nostri dell'area corrispondente alle attuali provincie di Udine e Pordenone. La pubblicazione è formata da undici saggi, tre dei quali firmati o coelaborati dal curatore Roberto Grandinetti; l'impianto di lavoro e la precedente produzione scientifica del curatore stesso, esaminata da quasi tutti gli altri autori nella stesura dei rispettivi saggi, rappresentano il vero e proprio trait d'union del volume dal punto di vista delle categorie interpretative utilizzate e della metodologia adottata (centrata soprattutto sull'elaborazione e successiva analisi di dati censuari e statistici). Pur mantenendo una significativa e utile coerenza tecnica di fondo, i vari saggi elaborano tuttavia ipotesi interpretative in una certa misura eterogenee e, per questo, complementari. Nonostante la periodizzazione scelta rimandi alla storia politico-istituzionale (il 
1964 segna, infatti, la nascita della Regione autonoma), il tema maggiormente approfondito è, come da progetto editoriale, il recente sviluppo economico del Friuli e il suo impatto con il territorio, inteso soprattutto come intreccio di cultura, pratiche sociali e identità. Le questioni legate direttamente alla storia della produzione materiale abbracciano quindi cinque saggi, cioè circa la metà dell'intero volume, a testimoniare come i cambiamenti intervenuti nell'economia rappresentino la principale cesura storica del periodo per le loro ricadute sul piano collettivo. Gli altri saggi affrontano questioni strettamente legate a quella delle dinamiche economiche dell'area: il peculiare andamento demografico e insediativo; le lotte sociali; il terremoto del 1976 e i caratteri della ricostruzione. Solo due saggi, infine, trattano la storia politica in senso stretto, per quanto, anche in questo caso, il focus sia centrato sull'apporto dato dalle istituzioni locali e dai partiti allo sviluppo economico del territorio.

L'analisi della recente e recentissima evoluzione economica friulana e del rapporto tra produzione, territorio e cultura, muove in questa pubblicazione dalla oramai acquisita appartenenza del Friuli alla "Terza Italia", un modello teorizzato per primo dal sociologo Arnaldo Bagnasco ma che lo stesso Grandinetti, con la sua precedente e sterminata produzione scientifica dedicata all'economia e alla società friulana, ha contribuito a definire ulteriormente e a verificare empiricamente. Il Friuli, infatti, rimasto parzialmente ai margini del vero e proprio boom economico degli anni Sessanta (avendo dovuto superare una fortissima crisi economica manifestatasi tra gli anni Venti e gli anni Cinquanta), come altre regioni dell'Italia centrale e del nordorientale a partire dagli anni Settanta ha vissuto uno sviluppo industriale rilevante e pervasivo quanto lo era stato quello del "triangolo industriale" nel decennio precedente. Il modello della "Terza Italia", così come l'analisi della recente storia del Friuli, permette di sfumare la tradizionale dicotomia storica (e sto- riografica) italiana che separa idealmente l'area del sottosviluppo economico relativo, il Sud, dall'area segnata dalla grande impresa, quel Nordovest che in precedenza aveva trainato i livelli di occupazione industriale e l'economia italiana, nonché imposto nei suoi caratteri di fondo il modello di sviluppo nazionale. Infatti, nella "Terza Italia" della fine del secolo precedente, le isole industriali "tradizionali" pur incidendo a livello statistico in modo significativo nell'andamento dei livelli produttivi ed occupazionali (su tutti, in Friuli, spiccano i casi dell'azienda elettromeccanica Zanussi di Porcia e della meccanica-siderurgica Danieli di Udine), non sarebbero riuscite a definire i caratteri e le dinamiche sociali ed economiche dell'intero territorio, segnato piuttosto dalle piccole imprese familiari diffuse, dal decentramento produttivo con conseguente riduzione del pendolarismo, dalla flessibilità nella produzione e nel costo del lavoro, dall'alta natalità e mortalità di imprese, da un modello di consumi ibrido che non si può identificare né con quello contadino tradizionale né con quello urbano, dalla conseguente riduzione ai minimi termini della conflittualità sociale (per la disponibilità di attività integrative al lavoro industriale, per il basso costo e la qualità della vita favorite dal decentramento). Quindi, nel Friuli, la nascita di nuove imprese medie o piccole è stato, almeno fino agli anni Novanta, un fenomeno pervasivo, alimentato da fattori culturali che legittimavano il lavoro autonomo e l'iniziativa imprenditoriale. In questo contesto la nascita di nuove aziende avveniva spesso per gemmazione (spin-off) da una entità aziendale già esistente e si sostanziava in una sua replica, ossia come una impresa subfornitrice e a cui l'impresa-madre poteva esternalizzare alcune attività o addirittura fornire il capitale fisso: viene citata a tal proposito l'emblematica testimonianza di un ingegnere della Danieli a cui la proprietà avrebbe suggerito in più occasioni "se c'è un operaio che vuole lavorare a casa, che ha bisogno di una macchina, gliela dia, tanto lavora per 
noi [come subfornitore]" (p. 12). Inoltre, nella "Terza Italia" in generale e nel Friuli in particolare si è assistito alla formazione dei distretti manifatturieri cioè aree a specializzazione produttiva (a loro volta spesso generate da precedenti tradizioni artigianali) in cui un ampio numero di piccole o medie aziende interdipendenti dà vita a un sistema produttivo che si rivolge all'esterno solo per il reperimento delle materie prime e per lo smercio del prodotto finito (per la regione nordorientale vengono qui analizzati i casi dei distretti della sedia, del mobile, dell'agroalimentare, del coltello, della termomeccanica, della pietra piasentina, dell'informatica sviluppatisi tutti in comuni non capoluogo contigui).

Le peculiarità della storia economica friulana rispetto ad altre regioni della "Terza Italia" andrebbero ricercate nel ruolo attivo svolto dalla politica industriale della Regione Autonoma (che, sfruttando le prerogative previste dallo Statuto, ha indirizzato il credito, gestito i finanziamenti statali e sostenuto la formazione dei distretti), e in quello della ricostruzione successiva al terremoto del 1976. La mobilitazione seguita all'evento sismico avrebbe accelerato, infatti, lo sviluppo già in atto o perlomeno, secondo l'originale ed eccentrica interpretazione di Marco Puppini, procrastinato il manifestarsi della crisi, con riferimento soprattutto alle ricadute nel settore edilizio che aveva sostenuto l'economia friulana nel primo ventennio postbellico (alimentandosi allora con le rimesse degli emigrati e con i finanziamenti statali, cfr. pp. 291 e ss.). Il terremoto del 1976 e la successiva risposta del territorio e dei friulani all'estero hanno rappresentato a ogni modo un potente fattore di coesione sociale e di costruzione identitaria con precise ricadute anche nell'opinione pubblica nazionale, non privo di conseguenze sul piano economico. Non a caso, infatti, il successo del "modello Friuli" di ricostruzione post-terremoto (cfr. il saggio di Luciano di Sopra) viene ricondotto alle stesse peculiari caratteristiche positive che, secondo molta pubblicista e l'im- maginario collettivo, avrebbero connotato e favorito lo sviluppo industriale sopra decritto: lo spirito d'iniziativa e il pragmatismo degli individui e delle comunità; la mancanza di corruzione e la trasparenza nell'erogazione dei finanziamenti pubblici, con la riduzione ai minimi termini di contestazioni e conflitti; le positive ricadute sul piano sociale dei valori tradizionali fortemente intrisi di cultura materiale come il lavoro, la proprietà, la famiglia; la valorizzazione di un sistematico concorso dell'azione locale, in luogo del tradizionale centralismo dello Stato (un caso effettivamente unico nella storia delle ricostruzioni post-terremoto italiane, dal momento che i fondi statali per la gestione dell'emergenza e la ricostruzione sono stati interamente affidati agli enti locali, con risultati tecnici ed economici assolutamente soddisfacenti). La narrazione e la rielaborazione dell'evento sismico sono procedute in modo tale che generalmente la memoria sociale friulana e nazionale ha ricondotto alla ricostruzione post-terremoto l'origine del superamento della precedente arretratezza economica e dell'inversione della catena migratoria (entrambi i fenomeni sarebbero iniziati invece almeno un decennio prima: cfr. pp. 41-42 e il saggio di Javier Grossutti dedicato alla storia migratoria friulana). Tale anacronismo della memoria è qui segnalato ma non chiarito; per comprendere ulteriormente le ricadute identitarie dell'evento del 1976 sarà probabilmente necessario attendere le conclusioni della commemorazione del quarantennale, una soglia critica nella formazione della memoria sociale e istituzionale.

Quella del "modello Friuli" è quindi una storia a lieto fine, un gioco in cui tutti hanno vinto nonostante lo svantaggio di partenza? In altre parole: la storia economica scientificamente condotta permette di avallare effettivamente il mito di una regione che ha ideato e raggiunto autonomamente il proprio sviluppo grazie alle collettività, uomini e donne che, uniti e favoriti da pratiche di buongoverno locale, hanno lavorato di bessoi (da soli) fino a ri- 
solvere tutte le precedenti difficoltà e a superare la storica arretratezza? Si potrebbe dire di no. Innanzitutto risulta difficile confermare il supposto carattere endogeno e "spontaneo" della crescita industriale centrata su poche grandi aziende a guida familiare, sulla diffusa piccola impresa e sui distretti: si veda ancora il saggio di Marco Puppini in cui sono messi in luce i fattori di "dipendenza di un territorio da potenti gruppi e coalizioni di interessi [tra i quali la Fiat] esterni all'area, sia economici che politici, entrambi capaci di indirizzare parti importanti della sua evoluzione economica in un senso o nell'altro" (p. 290), ma anche di pilotare dall'alto la crisi e la destrutturazione delle grandi aziende a partire dagli anni Ottanta. Dagli anni Novanta la Regione autonoma, la cui classe dirigente tradizionale non è riuscita a sottrarsi alla bufera di Tangentopoli con arresti e indagini condotte anche a livello locale, ha dovuto rivedere il proprio modello di indirizzo e di sostegno all'economia per rispettare le regole della libera concorrenza europea, oltre che per sottrarsi alle crescenti critiche dell'opinione pubblica. La stessa piccola impresa manifatturiera è stata fortemente ridimensionata in seguito alla globalizzazione dei mercati e alla crisi mondiale: tra il 2001 ed il 2011 il Friuli Venezia Giulia ha perso il 20,5\% delle unità locali (dato leggermente superiore alla media nazionale) ed il $15,2 \%$ degli addetti (dato inferiore del $4 \%$ alla media nazionale) nonostante il "ricambio" demografico garantito dalla nuova immigrazione. Lo stesso modello di conduzione familiare, basato sul learning by doing (tradotto: innovazione di processo e di prodotto senza ricerca), che fino al nuovo secolo ha limitato ai minimi termini l'impiego di manager e di altre figure professionali ad alta qualificazione, si è dimostrato incapace di affrontare le sfide poste dall'internazionalizzazione dei mercati. I distretti, hanno subito un lento processo di despecializzazione, in seguito al quale sono emerse alcune aziende leader di medie e grandi dimensioni che si trovano nella condizione di dover aprire le fasi intermedie della produzione a soggetti operanti all'esterno del distretto stesso: i saggi di De Marchi-Grandinetti e di ChiarvesioTabacco, delineano le evoluzioni possibili delle scenario presente, dopo averne rilevato le criticità. Rimangono infine ancora irrisolti i problemi specifici della montagna, dove lo spopolamento continua inesorabilmente (con conseguenti problemi ambientali legati all'abbandono dei terreni un tempo coltivati, cfr. il saggio di Marangon-Troiano dedicato al sistema rurale), e quelli legati alla mancata integrazione economica tra il Friuli propriamente detto e Trieste, una "città senza provincia", questione che assieme ai recenti progetti governativi neo-centralizzatori, mette ancora oggi in discussione l'esistenza stessa della Regione Autonoma e del suo Statuto.

A conclusione di tali note, può essere utile tentare un provvisorio e sintetico bilancio sulla collana Il Friuli, storia e società. Gli obiettivi posti nel primo volume, pubblicato nell'oramai lontano 1997, sembrano a chi scrive pienamente raggiunti: sovrapporre o mettere in connessione dialettica i tempi lunghi dell'economia, della dinamica sociale, dell'ambiente con i tempi brevi (per il Novecento, brevissimi) della storia politico-istituzionale; fornire una lettura unitaria, di ampio respiro e multidisciplinare della storia contemporanea dell'area friulana, prescindendo dall'oramai obsoleta categoria del "progresso". Viene parzialmente lasciata aperta una domanda, che rappresenta tra l'altro uno dei presupposti della presente avventura editoriale: in che misura è lecito parlare del Friuli, cioè delle attuali provincie di Udine e Pordenone, come di una "regione storica" di lungo periodo distinta sia dal Veneto che da Trieste? Si tratta di una questione alla quale i sei volumi curati dall'Istituto friulano offrono consapevolmente solo parziali risposte, ma nei quali, viceversa, è possibile trovare dei potenti e moderni strumenti analitici per gli studiosi che nel nuovo secolo vorranno cercare di risolvere l'aporia.

Alessio Marzi 


\section{Volti del fascismo}

Matteo Millan, Squadrismo e squadristi nella dittatura fascista, Roma, Viella, 2014, pp. 305, euro 26.

Il volume si inserisce all'interno del dibattito internazionale sui movimenti paramilitari in Europa sorti alla fine della Grande guerra e fornisce chiavi interpretative nuove sui tempi lunghi della violenza delle squadre fasciste italiane.

La nota tesi defeliciana sulla netta vittoria del cosiddetto "fascismo-regime" sul "fascismo movimento" individuava nel radicalismo e nello squadrismo due fenomeni residuali e controproducenti ai fini del consolidamento e dello sviluppo della dittatura. Viceversa, Millan conferma e arricchisce quanto sostenuto in precedenza da altri storici, fra cui Adrian Lyttelton e Salvatore Lupo, secondo i quali dopo la Marcia su Roma, la violenza perpetrata e la costante intimidazione degli avversari rappresentarono strumenti essenziali a disposizione dei governi per isolare ed eliminare le opposizioni, imporre la fascistizzazione e dimostrare l'impossibilità di percorrere strade politiche alternative. La classe dirigente fascista, delegando il "lavoro sporco" agli squadristi, secondo questa tesi, avrebbe potuto prendere le distanze dalle azioni più brutali e mantenere in questo modo un volto rispettabile di fronte all'opinione pubblica. Inoltre, le strutture e i movimenti paramilitari sarebbero rimasti uno strumento per l'affermazione di specifici gruppi di potere interni al fascismo, rappresentando una componente irrinunciabile per lo stesso Mussolini.

Più rapido sugli anni compresi tra il 1919 e il 1922, ma ricollegandosi alle conclusioni di Giulia Albanese sul "valore centrale della violenza di matrice squadrista per imporre il consenso e radicare la conquista del potere" (p. 26) e a quelle di Emilio Gentile sulla profondità della cesura del 28 ottobre, Millan concentra la propria attenzione sugli anni compresi tra l'i- stituzione della Mvsn e i primi anni Trenta, nei quali avvenne la "sistematica campagna denigratoria" e poi la repressione del gruppo di potere "arpinatiano" (p. 156).

Almeno due sono i proficui pilastri metodologici di Millan: l'utilizzo delle vicende biografiche come punti di osservazione privilegiata sui fenomeni politici generali e la continua attenzione all'intreccio tra l'analisi dei differenti contesti locali, con la costruzione di una comune "identità squadrista" (fondata proprio sull'esclusione dell'"altro", sulla distruzione, sulla violenza, sul cameratismo bellicoso, sulla ricerca di una vita "contro": come già aveva sostenuto magistralmente Sven Reichardt). Il continuo accostamento tra realtà territoriali differenti (per quanto forse eccessivamente schiacciate sul centro-nord), in particolare, permette a Millan di proporre accurate ricostruzioni fattuali della violenza squadrista successive alla Marcia su Roma e delle parabole biografiche dei soggetti coinvolti. Accanto alla storiografia più avveduta in materia e alle tradizionali fonti come le relazioni di polizia, i diari, le memorie, le cronache, i resoconti, gli incartamenti ad nomen della Segreteria particolare del duce e della Polizia politica, egli utilizza i fascicoli personali degli appartenenti alla milizia inviati al confino (una realtà restituita in questo modo a una rappresentazione soggettiva e concreta).

In seguito all'affinamento dell'apparato repressivo del regime e alle nuove direttive statutarie per il Pnf, nella seconda metà degli anni Venti (mentre la "rivoluzione fascista" non smetteva di essere celebrata), la legittimità dello squadrismo venne sospesa. Mentre lo Stato si "fascistizzava" e il partito assumeva sempre più, accanto a quella propagandistica, la funzione pedagogica di trasformare tutti gli italiani in "veri fascisti", l'utilità politica delle "gloriose" camice nere sembrò sbiadire repentinamente. Se numerosi squadristi (Scorza e Giunta, per citare due nomi celebri) riuscirono a trovare una collocazione all'interno degli organi centrali o periferici del regime, altri continuarono a commettere 
violenze o plateali provocazioni, subendo per questo emarginazione, carcere e confino. I camerati "indisciplinati” come Giampaoli (Milano), Arpinati (Bologna), Bonelli (Genova), Lugnan (Gorizia), Davoli (Pola), Albini (Novara), furono trattati come criminali comuni e, dall'interno della loro esclusione e/o prigionia, continuarono soventemente a esprimere quella "mentalità squadrista" che era stata il lievito della vittoria del 1922 e della stabilizzazione successiva.

Non tutti i destini degli "eroici camerati" furono uguali: per alcuni, e soprattutto per i disoccupati, ubriaconi, "amorali", "squilibrati” (p. 195) il confino rappresentò l'anticamera di una relegazione definitiva ai margini della vita politica e civile; per molti altri, la stessa misura sanzionatoria fu solo una fase transitoria e formativa, un "passaggio obbligato per una nuova vigilia" (p. 199). L'obiettivo politico della repressione fascista di quanto restava dello squadrismo delle origini non era infatti liberarsi di "vecchi arnesi" appartenenti a un'epoca ormai conclusa, ma quello di ottenere un'élite professionista della violenza, ossequiente e disciplinata per il raggiungimento di nuove mete. Infatti, il fascismo aveva necessità delle competenze squadriste nei sindacati, negli apparati polizieschi, nelle colonie, in Spagna, nel conflitto mondiale e nella successiva guerra civile. Queste funzioni avrebbero potuto essere vantaggiose per il regime solo nel caso in cui gli squadristi avessero riconosciuto l'obbedienza e la subordinazione alla struttura gerarchica del regime e a Mussolini. In cambio dell'ottenimento di un ruolo pubblico più o meno di prestigio (con un vantaggio privato), anche $\mathrm{i}$ camerati più irrequieti dovettero redimersi e riconoscere la sottomissione ai vertici, contribuendo in questo modo a creare un rapporto diretto e personalistico con i capi e soprattutto con il duce.

Le conclusioni di Millan sono assai proficue, ma meritano approfondimenti diacronici e sincronici: da una parte, l'origine delle squadre e della "brutalizzazio- ne politica" potrebbe rompere gli angusti confini del primo dopoguerra e spingere a indagare la violenza statuale e politica in Italia tra la seconda metà del XIX secolo e il 1914; dall'altra, la "schiuma dello squadrismo" (p. 194) richiede ancora approfondimenti per il periodo della guerra civile del 1943-1945. In questo modo sarà possibile sviluppare una solida storia comparativa e un confronto efficace con le ricerche europee sulla genealogia e lo sviluppo delle milizie armate tra le due guerre mondiali proposte recentemente da Robert Gerwarth e John Horne.

Andrea Ventura

Stefano Mangullo, Dal fascio allo scudo crociato. Cassa per il Mezzogiorno, politica e lotte sociali nell'Agro Pontino, 1944-1961, Milano, FrancoAngeli, 2015, pp. 240, euro 28 .

Tratto dalla tesi di dottorato, il lavoro di Stefano Mangullo è interessante per diversi aspetti. Il libro propone un'analisi capace di tenere insieme le questioni legate all'intervento pubblico straordinario nel Mezzogiorno e i processi di radicamento dei partiti dal secondo dopoguerra ai primi anni Sessanta. Con abilità l'autore riconnette storia economica e storia politica, basandosi su una documentazione frutto di un ampio lavoro di scavo archivistico e utilizzando il metro della storia locale per indagare le dinamiche centro-periferia. La dimensione spaziale scandagliata è la provincia di Latina. Già oggetto di un eccezionale esperimento di ingegneria sociale in epoca fascista, il territorio conosce con l'inclusione nell'area di intervento della Cassa per il Mezzogiorno una seconda fase di intensi cambiamenti diretti dall'alto. Come sottolinea in modo icastico l'autore "in circa un quarto di secolo si consumò il passaggio dalla lestra della palude al podere e dal podere alla fabbrica" (p.8).

Essenziale nel determinare le direttrici di questa trasformazione è il ruolo della Cassa per il Mezzogiorno. L'auto- 
re ne analizza l'azione e le ricadute a Latina ricostruendo gli stanziamenti a favore della provincia, per settori (bonifica, miglioramenti fondiari, bonifica montana, acquedotti e fognature, credito industriale, elettrificazione rurale) e per zone (Agro Pontino, Sud Pontino, aree interne settentrionali), ricavandone serie statistiche preziose per corroborare le ipotesi assunte. Se l'analisi dell'apporto infrastrutturale del primo tempo dell'intervento straordinario è approfondita e fornisce nuovi spunti di riflessione, tuttavia quella del secondo tempo, ovvero del processo di industrializzazione, risulta meno solida. Una mancanza che l'accesso alla documentazione del Servizio industria della Cassa, facilmente reperibile soltanto recentemente grazie al portale realizzato dall'Archivio centrale dello Stato, avrebbe potuto contribuire a colmare. Nondimeno, dal libro emerge chiaramente il salto di qualità compiuto dalla provincia, come risulta dalla lettura dei dati forniti dai due censimenti del 1951 e del 1961 e dall'incrocio delle informazioni tratte da altri studi (in particolare quelli elaborati dalla Svimez). Uno sviluppo economico di cui sono sottolineati con cura i limiti: gravi squilibri territoriali, un forte tasso di mortalità delle imprese, bassissimi salari.

L'analisi del rapporto tra Cassa per il Mezzogiorno e politica, tra intervento pubblico di matrice tecnocratica e dinamiche partitiche su scala locale, cui sono dedicati gli ultimi due capitoli, è estremamente convincente. Dopo aver analizzato come la Cassa incide sul tessuto economico e sociale della provincia, l'autore mostra come gli attori politici locali si approprino dell'intervento straordinario, tentando di influenzarne il corso e lo utilizzino come perno nella strategia di costruzione del consenso. La categoria interpretativa da cui muove il filo del ragionamento è quella del mediatore di Gabriella Gribaudi (Mediatori. Antropologia del potere democristiano nel Mezzogiorno, Torino, Rosenberg \& Sellier, 1980), ma le conclusioni ne divergono. L'autore non pare aderire al- la tesi secondo cui il sistema di mediazione democristiano conduce allo sviluppo di un modello di razionalità economica improntato a pratiche speculative e parassitarie. Piuttosto, lo studio sottolinea come, oltre ad alimentare fenomeni clientelari, il dirigente locale democristiano rivesta la "funzione 'compensativa' del deficit di comunicazione esistente tra il centralismo verticistico dell'intervento straordinario e gli enti periferici" (p. 140). Dei due elementi, clientelare e compensativo, è tuttavia il primo a essere ampiamente illustrato nel libro. Su questo terreno importanti analogie sul ruolo assunto dalla Dc a livello locale sono misurabili con quanto recentemente studiato per il caso della Ciociaria da Tommaso Baris C'era una volta la Dc. Intervento pubblico e costruzione del consenso nella Ciociaria andreottiana, 1943-1979, Roma-Bari, Laterza, 2011.

A Latina, il ruolo chiave di mediatore è impersonato dalla figura di Vittorio Cervone, segretario provinciale della Dc, commissario del Consorzio di bonifica di Latina, e dal 1953 deputato. La ricchezza del suo fondo d'archivio personale permette all'autore di fornire un quadro dettagliato dell'attività del dirigente democristiano nella sua funzione di anello di congiunzione con Roma, tra elettore ed eletto, e tra partito e amministrazione pubblica. Le pressioni sono esercitate verso il centro attraverso i contatti diretti di Cervone con il senatore Emilio Battista, con Giulio Andreotti, a lungo il suo capo corrente, con Pietro Campilli, per il suo incarico di presidente del Comitato dei ministri per il Mezzogiorno, con il presidente della Cassa Gabriele Pescatore. L'autore studia e documenta l'impegno profuso dalla Dc locale per far rientrare la provincia di Latina aldiquà della frontiera del Sud in modo da consentirle di approvvigionarsi alle risorse dell'intervento straordinario, le pressioni per accelerare i lavori volti alla costruzione di infrastrutture, ma anche per controllare le assunzioni negli enti locali, per sollecitare l'esame e l'approvazione delle pratiche di finanziamento del- 
le imprese. Il salto di qualità avviene nel biennio 1953-1954, quando la pratica della raccomandazione diventa metodica e sistematica e dalle amministrazioni pubbliche dilaga nelle fabbriche. In cambio dell'interessamento presso gli enti finanziatori, gli imprenditori garantiscono l'assunzione dei nominativi forniti dal partito. L'elusione della legge sul monopolio statale del collocamento della manodopera assume così proporzioni vaste ed è fortemente "caldeggiata dalla Dc" (p. 143). Le sue sezioni assolvono, in questo quadro, la funzione di primo collettore dei desiderata provenienti dagli "amici", alla cui ricezione è preposto un funzionario in pianta stabile.

Dallo studio degli scambi epistolari di Cervone, si chiariscono anche le differenze di prospettiva e di percezione delle priorità tra periferia e centro. Localmente la Cisl e la Dc sembrano dimenticare in prossimità delle scadenze elettorali le finalità dell'azione della Cassa. Il tentativo - non riuscito - di convincere Campilli dell'opportunità di limitare l'impiego di mezzi meccanici durante i lavori di bonifica per garantire un maggiore utilizzo di manodopera ne è un esempio significativo. Pesa l'obiettivo, di cui l'approccio Dc alle vicende della Cassa è parte integrante, del contenimento delle sinistre. Questo genere di politica "luddista", tuttavia, non deve far pensare all'assenza di una cultura economica produttivistica nella classe dirigente locale democristiana. La politica dei "ponti d'oro" offerta alle imprese per favorirne l'insediamento nel territorio attesta l'importanza che le amministrazioni bianche attribuiscono al processo di industrializzazione in corso.

$\mathrm{Su}$ questa linea si trovano spesso le sinistre. Il libro analizza l'originario "contadinismo" del Pci, i ritardi con cui si rapporta alle trasformazioni economiche della provincia, ma descrive anche l'impatto che ha l'azione della Cassa per il Mezzogiorno sulla dirigenza comunista locale. Da un lato, coerentemente con la linea nazionale del partito, i comunisti latinensi dirigono lotte contadine, promuovono proteste attra- verso l'invio di delegazioni di disoccupati presso le autorità provinciali e centrali, effettuano scioperi a rovescio col fine di controllare e stimolare l'attività della Cassa di cui stigmatizzano le inefficienze. Dall'altro lato, anche per la vicinanza con l'impianto riformatore sotteso al Piano del lavoro elaborato dalla Cgil nel 1949, i comunisti locali finiscono per aderire alla visione di cui è portatore l'intervento straordinario.

La storiografia e ancor più l'uso pubblico della storia si dividono nel valutare l'esperienza rappresentata dalla Cassa per il Mezzogiorno. Alla lettura incentrata sul carattere prevalentemente clientelare e corruttivo della sua azione, nonché fonte di ingenti sprechi di risorse pubbliche, si oppone quella che vi riconosce un motore fondamentale della modernizzazione del Sud d'Italia. Lo studio di Mangullo contribuisce con originalità a ripensare la storia del ruolo dell'intervento straordinario dialogando con entrambe le tesi e, al contempo, mettendole in discussione.

Massimo Asta

\section{Il cinema e la storia}

Alfonso Venturini, La politica cinematografica del regime fascista, Roma, Carocci, 2015, pp. 222, euro 23.

Nella vasta produzione storiografica dedicata, sin dalla fine degli anni Sessanta, al cinema nel ventennio fascista, gli aspetti economico-politici della questione sono stati senza dubbio tra i più approfonditi. Eppure l'emergere di approcci nuovi all'argomento, scaturiti da cantieri di ricerca italiani e internazionali, sta contribuendo se non a scardinare paradigmi interpretativi dati per consolidati, almeno a imporre una loro ricalibrazione. È il caso del volume di Alfonso Venturini che torna a occuparsi del tema concentrando l'analisi sulla politica del regime dopo la nascita della Direzione generale della cinematografica nel settembre 1934 e scegliendo 
di restringere l'oggetto di indagine ai film di finzione (escludendo, dunque, la produzione dell'Istituto Luce) per meglio illuminare le complesse interazioni pubblico-privato.

L'autore guarda al tema da un'ottica prevalentemente di storia economica, ma entra con disinvoltura nel merito degli aspetti politico-ideologici agganciando la riflessione al più ampio dibattito storiografico. Del resto lo stesso Venturini ha anticipato i risultati delle sue ricerche nel volume collettaneo curato da Pietro Cavallo, Luigi Goglia e Pasquale Iaccio (Cinema a passo romano. Trent'anni di fascismo sullo schermo (1934-1963), Napoli, Liguori, 2012), un lavoro che meglio di altri pone in evidenza la maturazione di "una nuova coscienza storiografica del cinema italiano" (come la definisce Gian Piero Brunetta nella Prefazione) derivante dal sempre più proficuo incontro tra il versante della storia contemporanea e quello della storia del cinema.

Il punto di forza della ricerca di Venturini è rappresentato dalle fonti d'archivio utilizzate (in primis il fondo lasciato da Giacomo Paulucci di Calboli, che fu a capo prima del Luce e poi dell'Enic, conservato all'Archivio di Stato di Forlì, e l'Archivio storico della Banca nazionale del lavoro dove sono conservati i libri verbali della Sezione del Credito cinematografico) che permettono all'autore di porre nuove domande agli oggetti di studio. Non che vengano messi in discussione gli aspetti essenziali della politica cinematografica fascista sin qui sottolineati dalla storiografia: quella sostanziale "schizofrenia" del regime nell'approccio all'industria cinematografica (per usare un'efficace espressione di Vito Zagarrio), che alternò — una volta rotta l'inerzia totale degli anni Venti — velleità di quasi completa statalizzazione sul modello nazista, a politiche in favore dell'autonomia degli industriali del cinema sul modello del capitalismo "individualista" americano. Ma, seguendo lo snodarsi dei dibattiti intorno al varo delle principali leggi e alla nascita delle istituzioni cinematografiche, Venturini riesce a mostrare come l'assenza di un disegno organico e razionale sia dipeso da una molteplicità di fattori, non sempre immediatamente evidenti.

Dai capitoli dedicati agli anni di Luigi Freddi alla guida della Direzione generale (1934-1939), viene bene in risalto quanto la politica del regime, lungi dal nascere da un disegno condiviso ispirato da Mussolini, fosse fortemente condizionata dalla personalità del primo direttore, al quale, com'è noto, si deve il tentativo più strutturato di esercitare un potere assoluto e discrezionale su tutta l'industria del cinema. Al vaglio delle nuove fonti emergono con chiarezza le difficoltà e le contraddizioni della politica di Freddi, minata dalle resistenze interne alla stessa compagine governativa e dai veti degli industriali, ma anche, al fondo, dall'incapacità di trovare una sintesi soddisfacente tra le necessità del mercato e le esigenze della propaganda. Il rafforzamento del controllo politico fu evidente in tutti i settori: la legge del giugno 1935 dotò l'industria cinematografica di una serie di inediti sostegni economici, ma fortemente dipendenti dal potere della Direzione (gli anticipi ministeriali ai produttori e la concessione di mutui da parte dalle nuova Sezione del credito cinematografico della Bnl); con la nascita dell'Enic lo Stato entrò prepotentemente nella distribuzione e nell'esercizio; infine la Mostra del cinema di Venezia passò, a partire dal 1935, sotto la completa orbita statale. Eppure, al netto di questi interventi, i progetti di statalizzazione del cinema e l'idea di Freddi di promuovere una cinematografia di regime che, senza essere apertamente propagandistica, rispondesse alle logiche e agli intenti del fascismo, si rivelarono di problematica applicazione. Intanto, fa notare Venturini, l'Enic, pur sotto l'accorta gestione di Paulucci di Calboli, fu ben lontano dal raggiungere una posizione monopolistica nei settori dell'esercizio (arrivando al 25-30 per cento di incassi sul totale nazionale nel 1940) e della distribuzione (quote di mercato inferiori al 20 per cento dei film italiani, che 
si abbassavano al $10 \%$ includendo i film esteri). Vanno poi tenute in conto le interferenze delle "superiori autorità" del regime sull'attività della Sezione del credito cinematografico, che più di una volta (come nel caso emblematico del salvataggio degli stabilimenti di Tirrenia fondati da Giovacchino Forzano) costrinsero l'ente a compiere operazioni che non avevano nulla a che vedere con la produzione o con la promozione di film a carattere politico o propagandistico. A conti fatti attraverso la legge degli anticipi, lo Stato investì su un numero non elevato di film che veicolavano contenuti in linea con le idee di Freddi (1/5 della produzione italiana del triennio 1935-1938), per poi fallire clamorosamente il progetto più ambizioso - la produzione di Scipione l'africano - che avrebbe dovuto esaltare la potenza del regime e la definitiva rinascita del cinema italiano. È infatti, secondo l'autore, il flop (economico e politico) di questo film — al cui iter produttivo è dedicata un'interessante disamina sulla base della nuova documentazione - che decretò la caduta in disgrazia di Freddi e il capovolgimento della politica cinematografica del regime.

Il nuovo corso inaugurato dalla legge Alfieri del giugno 1938 segnò una sorta di ritorno al passato (l'erogazione di contributi "a pioggia" senza distinzioni di sorta e in maniera proporzionale agli incassi del botteghino, come con la legge del 1931), sancendo da un lato la ritirata dello Stato a un ruolo assai meno invasivo (mettere le regole, stimolare, e assistere l'azione dei privati), dall'altro la vittoria degli industriali del cinema, completata nel 1941 con la nomina di Eitel Monaco, per anni ai vertici della Federazione nazionale degli industriali dello spettacolo, a capo della Direzione generale. A ben vedere la capacità degli industriali del cinema di ottenere, a dispetto dei tentativi di controllo totale del regime, il più alto grado di protezione da parte dello Stato e il massimo profitto dei privati (anche la creazione di Cinecittà, in fondo, si rilevò utile soprattutto a questo scopo), è il dato che più emerge evidente dalla rico- struzione di Venturini. Pure rispetto all'istituzione del monopolio (settembre 1948) gli industriali riuscirono a far passare imbastendo difficili trattative, ben documentate nel volume - un loro progetto di revisione che toglieva potere all'Enic, istituendo una società di gestione autonoma per l'acquisto e l'importazione delle pellicole estere (l'Enaipe).

È però probabilmente il tema della censura, argomento che puntella tutta la trama narrativa, che più si presta a far da termometro sia alla condotta ondivaga del regime, che al manifestarsi costante del potere contrattuale degli industriali. Freddi impose un cambiamento "qualitativo" che implicò l'applicazione di criteri funzionali al suo disegno di fascistizzazione del cinema, anche se non sempre univoci: in sintonia con la posizione della Chiesa prevalsero considerazioni di ordine morale, ma non di rado pesarono valutazioni di ordine estetico (come nella mancata censura di Tempi moderni di Chaplin) o un insieme di ragioni politiche e commerciali (è il caso delle pressioni sui produttori hollywoodiani per edulcorare i contenuti antifascisti). Negli anni del monopolio, e più ancora in quelli di guerra, rileva Venturini, a prevalere nettamente furono invece gli interessi commerciali: a imporre l'allentamento dei freni e un atteggiamento più indulgente e permissivo della censura, non furono tanto ragioni ideologiche quanto le petizioni di Paulucci di Calboli e, soprattutto, degli industriali, preoccupati - in linea con gli obiettivi che caratterizzarono gli ultimi anni della politica cinematografica fascista - di sostenere la crescita della produzione.

Gianluca Della Maggiore

Paola Bonifazio, Schooling in Modernity. The Politics of Sponsored Films in Postwar Italy, Toronto-Buffalo-London, University of Toronto Press, 2014, pp. 308, sip.

Paola Bonifazio è assistant professor di Italiano alla University of Texas di Austin. Come si evince dal suo curriculum, fa par- 
te di quell'ampia schiera di studiosi e studiose provenienti dall'Italia che negli ultimi decenni - in questo caso dopo la laurea conseguita alla Cattolica di Milano - hanno completato il proprio percorso di formazione nelle università dei paesi anglosassoni e lì hanno poi potuto intraprendere la carriera accademica. Il settore disciplinare nel quale si collocano le sue ricerche è quello dei Film and Media Studies.

Schooling in Modernity prende in esame i filmati informativi e di propaganda girati su commissione di agenzie governative e di soggetti privati nell'Italia del secondo dopoguerra (l'arco cronologico considerato si estende dal 1948 alla fine degli anni Cinquanta). Tra i committenti troviamo da un lato il Centro di documentazione della Presidenza del Consiglio e la divisione cinematografica dell'Eca (Economic Cooperation Administration, l'agenzia statunitense responsabile dell'attuazione del Piano Marshall), dall'altro organizzazioni non governative come l'Unione nazionale per la lotta contro l'analfabetismo e grandi gruppi industriali come la Fiat, l'Olivetti e la Edison. Si tratta di un vasto corpus costituito da centinaia di cortometraggi, meritoriamente schedati nell'utile filmografia che correda il testo. Come sottolinea l'autrice, nonostante venissero presentati al tempo come documentari, in realtà essi contengono spesso nella loro trama narrativa evidenti elementi di fiction. Proiettati non solo nei cinema prima dei film, ma anche in luoghi pubblici come le piazze (grazie a proiettori mobili) o nei dopolavoro aziendali, avevano un'ampia circolazione che consentiva almeno potenzialmente di raggiungere un gran numero di spettatori.

Bonifazio adotta un approccio teorico di matrice foucaultiana per analizzare i filmati nei loro intenti informativi e pedagogici, come strumenti attraverso cui gli italiani potevano imparare a conoscere i vari aspetti del processo di modernizzazione che il loro Paese stava vivendo nel dopoguerra, naturalmente grazie al generoso aiuto americano, alla provvida azione del governo e all'encomiabile impegno delle imprese, come era di volta in volta debitamente evidenziato nei corti. L'autrice fa ricorso, in particolare, al concetto di governamentalità, messo a punto dal filosofo francese nei corsi tenuti al Collège de France nella seconda metà degli anni Settanta: concetto che è stato largamente ripreso negli studi culturali e ha conosciuto grande fortuna soprattutto nel mondo anglosassone. In quest'ottica, i filmati sono visti come dispositivi per governare la popolazione attraverso rappresentazioni che da un lato mettevano bene in luce il ruolo guida delle organizzazioni committenti nel processo di modernizzazione e la cura dei loro rappresentanti per le esigenze della cittadinanza (o dei propri dipendenti), dall'altro presentavano situazioni, figure e modelli di comportamento esemplari che sottintendevano un preciso set di valori e virtù volti a regolare le attitudini e la condotta degli spettatori indirizzandoli verso il conseguimento del benessere e della felicità in un quadro di progresso materiale, pace sociale, stabilità politica e mantenimento dei ruoli di genere tradizionali (un aspetto, quest'ultimo, cui l'autrice presta particolare attenzione). Il titolo del libro rimanda appunto all'idea che per mezzo di tali filmati gli italiani venissero istruiti o ammaestrati alla modernità in questo duplice senso.

Il volume si compone di sei capitoli articolati su base tematica, preceduti da un'introduzione. Il primo capitolo prende in esame i filmati sulla ripresa economica, il lavoro e il contrasto alla disoccupazione; il secondo si concentra sui filmati industriali dedicati agli impianti, ai prodotti e alle iniziative assistenziali e sociali delle grandi imprese; il terzo guarda ai filmati sul problema delle abitazioni nelle città e nei centri rurali e sui piani di edilizia residenziale pubblica; il quarto a quelli sul divario Nord-Sud e il suo supposto superamento per effetto della modernizzazione del Mezzogiorno; il quinto tratta della cinematografia scolastica e dei filmati sul Piano Marshall e sulla ricostruzione e lo sviluppo a livello europeo; l'ultimo esami- 
na infine i filmati di taglio storico dedicati a vicende del passato recente come la seconda guerra mondiale, la Liberazione e la ricostruzione. Particolarmente efficace, nel quadro dell'impostazione teorica e metodologica del lavoro, risulta nel primo capitolo (pp. 30-32) l'analisi del cortometraggio Tiriamo le somme (prodotto dall'Istituto Luce per il Centro di documentazione della Presidenza del Consiglio nel 1953), che consente all'autrice di riprendere e sviluppare l'analogia tra governo dello Stato e gestione della famiglia cui ricorre Foucault nella sua analisi della governamentalità.

Pur tenendo nel debito conto che l'autrice non è una storica e che l'analisi si situa al livello delle rappresentazioni e delle pratiche discorsive piuttosto che delle effettive dinamiche politiche e sociali, non si può non segnalare qualche imprecisione fattuale che emerge qua e là nel testo: Fanfani, per esempio, non ricoprì mai la carica di ministro dei Lavori pubblici, come si legge a p. 88; fu invece in veste di ministro del Lavoro e della previdenza sociale (nel V governo De Gasperi) che lanciò il piano Ina Casa. Ciò non toglie che Schooling in Modernity sia un libro ben documentato, vivace nell'esposizione e ricco di spunti: esso può costituire dunque una lettura di sicuro interesse anche per gli storici e le storiche dell'Italia contemporanea.

Bruno Bonomo

\section{Italiani al fronte}

Quinto Antonelli, Storia intima della Grande guerra. Lettere, diari e memorie dei soldati dal fronte, con un dvd del film di Enrico Verra, Scemi di Guerra, Roma, Donzelli, 2014, pp. 312, euro 32.

In questo volume Quinto Antonelli raccoglie le voci, anzi le parole scritte da tanti soldati italiani al fronte e conservate all'Archivio della scrittura popolare, presso il Museo storico del Trentino, in lettere, cartoline, diari e memorie. Si tratta di un lavoro fondamentale per capire il valore della scrittura come rifugio e come consolazione nei momenti in cui i soldati non sono impegnati in prima linea o a scavare trincee o a spalare la neve.

Per avere un'idea del volume, se ne legga un passo (un po' lungo, ma significativo): "Davanti a me in basso si trovava un Russo sulla 40na d'anni, questo vistomi davanti mi invitò alla lotta, presi io pure lo schioppo e mi misi sull'attenti, in diffesa, io non volevo ucciderlo ma non desideravo restar morto neppur io, la lotta non possio descrivere, non ne ho il coraggio, dopo pocchi secondi mi accorsi che perdevo sangue alla mano destra, i miei occhi si infiamarono, mi trovavo in forte delirio, presi con forza l'arma e la gettai contro il povero disgraziato, chiusi gli occhi per non vedere, e, gli apersi gli vidi il sangue a scorrere, la mia baionetta era penetrata nel collo dalla parte destra, sotto la clavicola, la mia arma le era penetrata circa 5 cent. il sangue sortiva e si sparpagliava sopra il vestito, egli aveva abbandonato l'arma appoggiato ad un tom di terra colle mani giunte mi stava pregando la vita" (p. 184). Sono ricordi di Alfonso Cazzoli, tipografo trentino di Tione nato nel 1887 e arruolato nel 1915 nell'esercito austroungarico, combattente sul fronte galiziano. L'8 giugno 1916, dopo diversi tentativi, riuscì a disertare e a consegnarsi ai russi. Le memorie di Cazzoli sono solo uno dei testi che compongono questa toccante Storia intima, composta per lo più dalle tante testimoniante provenienti da soldati e subalterni (operai, contadini, artigiani, tipografi). Gli autori non hanno l'ambizione di lasciare qualcosa ai posteri ma solo quella di rivolgersi ai propri familiari, e sono sudditi italofoni dell'Impero austroungarico.

La guerra in questi testi è configurata in tutto il suo orrore con quel carattere di violenza che traspare dalle parole di quanti l'hanno combattuta e vissuta in prima linea. Vi è in chi esprime la voglia di far capire come si vive in quella condizione: "Caro Agostino, o saputo dei richiama- 
ti che son venuti a dosso, che qui sul Cremasco digono ancora che noi qui in prima linea abbiamo tutto, se ne senti qualcuno dirli a nome mio: primo si dorme per terra e ora siamo pieni di pedocchi e abbiamo ancora adosso la biancheria che amnno dato quando siamo stati richiamati “ (Stefano Manclossi, pp. 252-253). Poi ancora c'è chi, come un Francesco Giuliani, esprime, oltre lo sbigottimento e il terrore un rancore verso i superiori e verso la classe dirigente che ha voluto la guerra, nasce in loro una vera e propria rivolta morale che si trasforma in spirito pacifista: "Io non ho stima, né simpatia per quelli che sono i coraggiosi eroi; in guerra tutti quelli che vi sono distinti come eroi sono assassini, il vero eroe è quello che mette in pericolo la propria vita per salvare quella degli altri. Nell'austriaco io non vedo il nemico come mi si vuol far credere, che devo dargli la caccia ed ammazzarlo ad ogni costo; penso che nel suo villaggio ha lasciato i suoi cari dai quali fu strappato come io lo fui da te. Nel mio cuore non c'è la frenesia omicida, rifletto che la vita di tutti è cara, ed ogni soldato morto o amico o nemico resta una madre senza figlio, o una sposa senza sposo o dei figli senza padre. L'uomo non deve essere il cane aizzato che si avventa; dalla natura ha avuto il dono del cervello, deve cercare di capire tutto, pensare e riflettere, e quando è spinto a fare il male si deve guardare di non farlo" (p. 259).

Per i soldati anche se poco alfabetizzati, molto spesso del tutto analfabeti, il rito della scrittura diventa indispensabile è l'unico legame con le famiglie, l'unico modo per sentirsi ancora vivi, ma diventa certe volte anche un rito ripetitivo come nel caso di Ettore Travostino: "Forse non avete torto di rimproverarmi, perché scrivo poco; ma io non saprei come fare altrimenti. Credo di aver sempre risposto alle vostre lettere e cartoline, e magari anche qualche volta in più. Che volete altro? Non posso certo inventarvi delle storie, per avere argomento di scrivere più sovente; e d'altronde non mi garba l'usanza di alcuni, che ogni giorno ripetono sempre le stesse parole" (p. 237).

I testi scritti vengono riportati da Antonelli senza alcun intento letterario, il criterio editoriale seguito è stato rispettare la loro veste linguistica e ortografica originale, lasciando intatta l'immediatezza, la freschezza e le difficoltà di espressione.

Allegato al libro figura un dvd del film di Enrico Verra: Scemi di guerra. La follia nelle trincee. Il documentario si confronta con la Prima guerra mondiale da una prospettiva raramente analizzata finora. La Grande guerra fu guerra di massa, di manipolazione delle masse, di spersonalizzazione degli individui: nel documentario grazie a immagini mute accompagnate dall'approfondimento di storici ed esperti vediamo alcuni risultati di tutto questo su quei soldati. Vediamo, per esempio, come un sopravvissuto alle trincee, costretto a vivere bombardamenti interminabili, terrorizzato dalle bombe chimiche, obbligato ad assalti che erano lotterie della morte si ammalasse di shell shock. Gli psichiatri del tempo li rimandavano al fronte dopo averli sottoposti a sedute di elettroshock. Il documentario è di forte impatto. Gli occhi e le espressioni di quei soldati ormai persi aprono a riflessioni sul destino dei singoli stritolati nella macina della Grande guerra.

Giuseppe Manias

Mario Avagliano, Marco Palmieri, Vincere e vinceremo! Gli italiani al fronte, 1940-1943, Bologna, il Mulino, 2014, pp. 376, euro 25 .

Il volume di Mario Avagliano e Marco Palmieri, entrambi giornalisti pubblicisti con una forte attitudine alla ricerca storica, tanto da essere impegnati da diversi anni rispettivamente il primo come direttore e il secondo quale membro del Centro studi della Resistenza dell'Anpi di RomaLazio, affronta un tema assi importante e molto discusso, quello del livello di "connessione sentimentale" dei soldati italiani 
con la guerra combattuta nel corso del secondo conflitto mondiale.

A partire dalla Storia della Resistenza italiana di Roberto Battaglia, si tendeva a collocare la rottura tra il regime fascista e il paese già alla promulgazione delle leggi razziali. La scelta poi di entrare in guerra al fianco della Germania nazista avrebbe costituito l'ulteriore momento di cesura, amplificato dalle successive sconfitte militari, sino alla caduta di Mussolini il 25 luglio 1943. Dagli anni Settanta in avanti la storiografia ha complicato questo quadro, evidenziando la centralità dell'esperienza bellica, in tutte le sue forme, quale momento di ripensamento del paese del suo rapporto con il fascismo. Lo evidenziavano già, a ben vedere, le memorie di Giorgio Bocca, Davide Lajolo, Nuto Revelli, le cui riflessioni sull'esperienza bellica dei soldati italiani insistevano sulla difficoltà del passaggio dalla guerra "fascista" a quella "partigiana". In questo quadro si era inserito Renzo De Felice, che nel 1990 nel primo tomo del volume Mussolini l'alleato. L'Italia in guerra, insisteva sul consenso a favore della partecipazione al conflitto mondiale da parte dei giovani formatisi sotto il regime, come dimostrava l'elevato numero di volontari.

Proprio sulla “qualità" dell'adesione alla guerra del regime la ricerca di Avagliano e Palmeri cerca di fornire nuove prospettive, grazie a un'attenta analisi sia della memorialistica, delle lettere passate al vaglio della censura e delle relazioni fiduciarie sulle truppe impegnate nei combattimenti. Pur tenendo conto delle caratteristiche di queste fonti, gli autori propongono una lettura assai interessante, concordando con quella più recente storiografia che ha posto l'accento sull'azione del fascismo per riplasmare in senso bellico l'animo degli italiani. L'analisi dei testi proposti dimostra sicuramente l'entusiasmo dei giovani verso l'ingresso in guerra dell'Italia fascista, ma anche una non secondaria penetrazione della propaganda del regime fascista nel loro immaginario. Giorgio Bussi, giovane studente universitario abruzzese, al momento dell'ingresso in guerra esulta perché "il Duce" ha "mantenuto la promessa del combattimento. [...] Si vedrà allora l'opera meravigliosa e incredibile della $\mathrm{Ri}$ voluzione continua riflessa e viva in noi, fatta da motore politico, impulso morale diventata costume, stile, sistema di vita" (p. 32).

I nemici dei primi mesi, gli inglesi, sono evocati secondo la rappresentazione caricaturale proposta dalla dittatura fascista, e questo elemento tende a radicalizzarsi nei mesi successivi quando le truppe italiane entreranno in azione prima nei Balcani e poi parteciperanno all'aggressione nazista all'Unione Sovietica. Lo scontro con gli slavi e anche il primo impatto con il movimento partigiano fa emergere chiaramente anche tra i soldati tematiche razziste ed imperiali, connotando fortemente l'occupazione militare in quelle realtà. Il tenente dei bersaglieri Nino Raimoldi, scrivendo alla sorella, parla di un "nemico bestiale, spietato che tenta in questo inverno di logorarci e di piegarci. Continuamente lancia le sue orde selvagge al macello. Cadono a centinaia, a migliaia, con una rassegnazione ed un fanatismo veramente orientale" (p. 111). L'invasione dell'Urss non solo amplifica questi temi ma li salda fortemente con l'anticomunismo. Questo in verità non ha soltanto connotazioni riferibili al fascismo, ma risente fortemente anche dell'ibridazione con la cultura cattolica, che finisce per rappresentare quasi in termini di "missione" religiosa la lotta al bolscevismo. Il soldato Secondo Sernaglia scrive di combattere "contro il bolscevismo nemico di ogni ordine sociale ed economico e per la salvezza della civiltà romana e cristiana" (p. 107). Più in generale la sensazione è che il mito già liberale di una "Italia più grande" si incontri con temi più propriamente fascisti. Se il bersagliere toscano Aminto Barsi scrivendo alla madre parla della "nostra Europa vessata dal giudaismo e dal capi- 
talismo anglosassone [...] coniugato con il bolscevismo facendo l'unione più paradossale che si possa immaginare" (p. 181), il volontario Armando Mancini richiama "la Patria, la famiglia, la terra dove si è nati" per rivendicare "il diritto di un grande popolo" come quello italiano (pp. 263-264).

In questo modo, come scrivono gli autori nell'Introduzione, saldando la nuova educazione con retoriche di più lungo periodo, "quella che è una guerra di aggressione, per la stragrande maggioranza degli italiani diventa, come risulta dalle lettere, una guerra difensiva e patriottica, oltre che santa. E per questo destinata alla vittoria" (p. 22).

Proprio questa interpretazione ci pone tuttavia una serie di problemi: il continuo richiamare nelle lettere alla vittoria e alla ferocia del nemico, al pari dei temi della propaganda del regime, poco ci dice se e quanto fossero mutati concretamente i comportamenti dei soldati italiani. Desiderare la vittoria finale nel conflitto e dirsi disposti a sacrificarsi per questa, anche quando come succede si cominciano a percepire più chiaramente i limiti del regime (anche se il mito di Mussolini sembra resistere più a lungo), non rientra forse nei meccanismi di socializzazione comunitaria propri di tutti gli eserciti in guerra? Lo stessa tendenza a ridurre la guerra "fascista" a guerra "patriottica" o addirittura "difensiva" non significa tutto sommato che il tentativo del regime di formare una coscienza guerriera, marziale, razzista e prevaricatrice si è concretamente scontrato con la tendenza nei soldati ad inquadrare il conflitto mondiale dentro rappresentazioni mentali più tradizionali?

Il volume rappresenta comunque un importante tentativo di andare verso una storia sociale e della mentalità dei soldati italiani nel secondo conflitto mondiale, che costituisce un tema cruciale anche per ragionare sugli esiti del tentativo totalitario del fascismo.

Tommaso Baris

\section{Oltre confine}

Vjekoslav Perica, Pax Americana na Jadranu i na Balkanu, Zagrabia, Algoritam, pp. 352, kune 149.

Il libro di Vjekoslav Perica Pax Americana na Jadranu $i$ na Balkanu [Pace americana nell'Adriatico e nei Balcani] si propone di riflettere in una prospettiva di lungo periodo sul ruolo giocato dagli Stati Uniti nell'area adriatica e balcanica durante il XX secolo mettendo in relazione tre periodi storici e le missioni militari a esse connesse: la missione americana presso Spalato dopo la Prima guerra mondiale, l'amministrazione anglo-americana a Trieste e gli interventi in Bosnia Erzegovina nel 1995 e nel 1999 in Jugoslavia (all'epoca composta da Serbia e Montenegro) e Kosovo. Analizzando l'interazione tra l'esercito statunitense e la popolazione locale, vengono messi in luce gli scambi culturali avvenuti durante le missioni, con una particolare attenzione per la penetrazione della cultura di massa occidentale e per la memoria dell'incontro con l'Altro nella memoria storica locale, jugoslava, italiana o post-jugoslava.

Al primo intervento statunitense del 1919 a Spalato, denominato dagli stessi contemporanei missione di pace, è dedicata la parte più ampia e dettagliata del libro. Si tratta di una missione trascurata sia dalle storiografie dell'area che da quella statunitense, sebbene essa sia stata un segno dei tempi: da una parte, richiamandosi per la prima volta ai principi espressi dal presidente Wilson si proponeva di mantenere la pace in un'area contesa tra il Regno d'Italia e il neonato Regno dei Serbi, croati e sloveni (che dal 1929 si trasformerà in Regno di Jugoslavia); dall'altra voleva prevenire un allargamento della rivoluzione comunista che aveva appena infettato la vicina Ungheria.

Sebbene non sia il focus principale del volume, significativa e vivida appare l'immagine dell'Adriatico come luogo di se- 
colare convivenza all'irrompere del secolo breve e dei nazionalismi, con l'impresa di D'Annunzio che porta a una destabilizzazione che si propaga a sud, verso la Dalmazia, mettendo in allarme la popolazione slava della città di Spalato che iniziò a guardare alla Jugoslavia, della quale era appena entrata ad essere parte, come a una protezione contro l'imperialismo italiano, che allo stesso tempo cercava di aizzare uno contro l'altro la componente serba e quella croata. E sullo sfondo degli avvenimenti politici appaiono un'identità dalmata sovranazionale successivamente distrutta dai nazionalismi e la conseguente costruzione di un'identità jugoslava.

In particolare, un tentativo di occupazione della città di Traù messo in atto da un seguace di D'Annunzio, che avrebbe potuto rappresentare la scintilla per un conflitto tra l'Italia e il vicino adriatico venne impedito dalle truppe americane di stanza nella vicina Spalato. Il favore che queste si erano guadagnati agli occhi di gran parte della popolazione slava spalatina, il carattere sempre più umanitario che la missione andò prendendo, insieme al soft power di un impero allora nella sua fase nascente furono le precondizioni per un'interazione tra le truppe straniere, che si fecero vettori di nuovi trend, nuovi valori e nuovi stili di vita, e la popolazione locale. Un contatto che, seppur durato due anni, ha lasciato tracce profonde nella memoria storica della città che lo ha fotografato nella sua cultura di massa (come le operette del compositore Ivo Tijardić in cui compaiono le figure dei marinai americani) o nello sport. All'inizio del secolo l'immagine degli Stati Uniti appariva fresca, ingenua, ma capace di creare intorno a sé il mito di coloro che aiuta i piccoli popoli.

La seconda parte del libro si concentra invece sulla missione angloamericana nella zona A del Territorio libero di Trieste dalla fine della Seconda guerra mondiale fino al 1954 quando l'intera zona passò all'Italia. Anche in questo caso emergono l'interazione con la popolazione locale, e in particolare con la componente italia- na, e la penetrazione delle influenze culturali occidentali in un territorio che a breve diventerà la periferia d'Italia, ma anche la porta verso l'Est, destinata ad aprirsi sempre più nel decennio successivo, lasciando passare alcuni degli stessi trend arrivati in Italia grazie all'esercito americano. L'autore si concentra sulla differenza di atteggiamento degli americani rispetto alla precedente missione: se in quella prima missione avevano preso le parti della popolazione slava, a Trieste gli americani si ergono a difesa dell'Italia. Un'affermazione che tuttavia potrebbe essere ulteriormente problematizzata considerando il rapporto ambivalente che i settori pro italiani della città ebbero con gli angloamericani, presentati nella narrazione nazionale prima come veri liberatori dopo i 40 giorni del potere jugoslavo, ma successivamente oppressori, potenza dominante che non esitava a sparare sui manifestanti.

Infine, l'ultima parte del libro è dedicata agli anni Novanta e ai due interventi statunitensi, quello del 1995 durante la guerra di Bosnia Erzegovina e quello del 1999 che diede inizio alla guerra del Kosovo. Mentre nel primo caso l'intervento americano contribuì alla fine dei combattimenti, l'attacco contro la Jugoslavia (allora composta da Serbia e Montenegro) fu, l'unico caso di potenza offensiva utilizzata dagli Stati Uniti. Quest'ultima parte del volume attenderebbe un ulteriore approfondimento, in merito al concetto di soft power, alle relazioni di potere instauratesi tra l'esercito statunitense e le popolazioni locali e al concetto di "umanitarismo" che secondo l'autore caratterizzerebbero anche l'intervento statunitense in Kosovo. Tuttavia questa prospettiva di lungo periodo, che collega il primo dopoguerra con il decennio che vide la disgregazione della Iugoslavia, per quanto problematica, offre al lettore delle occasioni di riflessione: per esempio il paragone tra il trattato di Rapallo (con cui il Regno d'Italia e il Regno dei serbi, croati e sloveni, dal 1929 Regno di Jugoslavia, definirono nel 1920 le loro frontiere) e il trattato di Dayton (che nel 
1995 mise fine alla guerra in Bosnia Erzegovina cristallizzando la situazione di pulizia etnica avvenuta sul suo suolo), come due trattati che non portarono né la pace né alcuna soluzione destinata a essere duratura.

L'importanza del libro si riscontra principalmente sia nella prospettiva di lungo periodo - che mette in relazione in un'ottica comparata gli interventi militari statunitensi in tre periodi storici lontani tra loro - sia nell'attenzione agli Stati Uniti come potenza dominante nel secolo che coincide con la sua ascesa e declino. Una prospettiva particolarmente interessante per le storiografie della regione - sia italiana che slovena e croata - che, nonostante l'uso di fonti angloamericane per l'analisi della questione di Trieste, hanno spesso mancato di riconoscere l'importanza degli equilibri internazionali rispetto ai rapporti bilaterali tra i due contendenti.

Francesca Rolandi

Francesco Fabbricatore (a cura di), $I l$ diario di Francesco Majone. Un carabiniere calabrese in terra d'Albania (1940-1942), Arcavacata di Rende, Istituto calabrese per la storia dell'antifascismo e dell'Italia contemporanea, 2015, pp. 142, sip.

Francesco Majone, nacque a Sambiase (Lamezia Terme) nel 1896. Arruolato nei Carabinieri, fu inviato per la prima volta al fronte nel 1918. All'età di quarantaquattro anni chiese e ottenne di essere trasferito in Albania per partecipare alla Guerra italo-greca, credendo in modo acritico nella presunta natura "patriottica" della guerra scatenata dall'Asse nei Balcani: "Nella mattinata si è sparsa la notizia fra le truppe del settore dell'arrivo in Albania del Duce e dell'occupazione della Bulgaria da parte di Hitler. Un'immensa gioia pervade l'animo dei soldati, che prevedono nella venuta del Duce la vittoria imminente della nostre armi" (p. 46). Poco dopo l'8 settembre 1943, ancora in Albania dopo un periodo di licenza, fu deportato dai tede- schi nei campi d'internamento in quanto "badogliano" non collaborazionista; divenuto antifascista, riuscì a rientrare in Italia (dove per molti mesi fu ritenuto morto) solo nel settembre 1945. Nel 1952 fu eletto sindaco di Sambiase nelle liste della Dc. Dopo la guerra, Majone, che da soldato usava documentare in modo piuttosto scrupoloso la sua attività, non riuscì mai a vedere riconosciuta la sua insufficienza respiratoria - una conseguenza di un enfisema polmonare contratto nel lungo periodo di internamento nei lager tedeschi - dal momento che durante la prigionia non aveva mai usufruito di assistenza sanitaria documentabile: non aveva mai chiesto alcun aiuto al personale dei campi per la paura di essere eliminato in quanto ammalato.

Dopo la sua morte, occorsa in Calabria nel 1974, la famiglia ha conservato una serie di carte personali relative al suo coinvolgimento nella Seconda guerra mondiale, che in questo volume vengono pubblicate integralmente: non solo il diario, come si evincerebbe dal titolo, ma anche fotografie, lettere scambiate con i familiari durante la prigionia tramite la Croce rossa, una parte dell'interessantissimo materiale di "propaganda sovversiva" che Majone aveva allegato al suo diario del periodo 1940-1942 dopo averlo recuperato vicino al fronte, altri documenti trovati dai curatori nell'Archivio dell'ufficio storico dell'Arma. Un secondo quaderno gli fu invece sequestrato dai tedeschi prima dell'internamento e non è mai stato recuperato.

La pubblicazione dei documenti è corredata da una scrupolosa introduzione storiografica in cui viene ricostruita la vicenda dei reparti con i quali Majone operò in Albania e da un'ampia serie di note esplicative che permettono di incrociare le informazioni contenute nei documenti con altre fonti storiografiche e d'archivio. La pubblicazione, impeccabile, è parte costitutiva di una serie di studi promossi dall'Istituto calabrese per la storia dell'antifascismo e dell'Italia contemporanea nella collana La memoria e la storia, che si pone lo sco- 
po di "scoprire i protagonisti minori degli eventi del passato" (p. 10) e che già in precedenza aveva dato spazio al tema della guerra italo-greca combattuta prevalentemente nell'Albania occupata dall'Italia.

Quali elementi di spicco risaltano dai documenti di Majone? Egli non partecipò mai direttamente ai combattimenti, poiché operò prevalentemente in attività di copertura e servizio territoriale, per quanto in prossimità del fronte (il campo dove erano insediati i Carabinieri comandati da Majone, alcuni dei quali successivamente distaccati e inviati al fronte, fu infatti più volte bombardato dall'aviazione greca, con la conseguente morte di alcuni commilitoni). In tale contesto egli ebbe invece frequenti contatti con la popolazione albanese: nel marzo 1941, per esempio, indagò assieme ad altri quattro militari su un duplice caso di omicidio, mentre nel gennaio del 1942 investigò su un incendio che aveva distrutto tre case a Korçë. Tuttavia Majone, nella sua scrittura asciutta, essenziale, acritica e quasi "burocratica" (pur trattandosi di un documento a uso personale), non si adoperò quasi mai per descrivere l'Albania e la sua popolazione, scegliendo di non affidare alla pagina scritta alcuna riflessione sulla situazione sociale e politica del paese adriatico occupato dall'Italia o considerazioni personali sul contesto umano nel quale si trovò a operare. Prova ne sia che classificò i volantini in lingua italiani lanciati sul campo dall'aviazione greca e quelli diffusi clandestinamente dalla Gioventù comunista d'Albania (da cui sarebbe nato il movimento partigiano) con lo stesso aggettivo: in entrambi i casi, infatti, egli definì tale materiale come (banalmente) "sovversivo" (p. 39 e p. 62). Lo "sguardo" di Majone sulla popolazione albanese ondeggia tra un atteggiamento paternalistico (rilevabile dall'uso di alcuni vezzeggiativi: "è un paesello albanese", p. 47), un superficiale interesse esotico (si vedano per esempio la fotografia della copertina che ritrae Majone in posa davanti a una moschea, o quella di p. 36 , in cui egli si fa ritrarre assieme ad altri due commilitoni e a una pittoresca guida albanese) e il relativismo culturale: "le donne non escono di casa per paura di essere viste. Di conseguenza tutti i lavori vengono eseguiti dagli uomini, compresi quelli di lavoro da biancheria ed andare ad attingere acqua dalla fontana. È il loro Maometto che vuole così” (p. 47). Paradossalmente, come rilevato dalla storiografia albanese, nella zona sud-orientale del paese le ragazze del posto avevano ricoperto un certo ruolo nella fase di formazione della resistenza, dal momento che la propaganda comunista aveva avuto una relativamente forte capacità di penetrazione nella scuola professionale femminile di Korçë, p. 129). Sul piano politico, emerge come gli albanesi, al pari dei civili italiani, fossero mobilitati a scopo propagandistico ("Il popolo di Coriza, unitosi ai soldati del presidio ha percorso le vie del paese con canti italiani inneggiando a S.M. il Re Imperatore ed il Duce”, p. 55), oltre che considerati un popolo "colonizzato" e quindi pericoloso, da privare dei propri mezzi di difesa (sono infatti documentati continui sequestri di armi e materiale esplosivo nelle abitazioni private, in almeno un caso un lascito dall'esercito greco in fuga che forse sperava così di facilitare la formazione di un movimento partigiano) e, eventualmente, da reprimere ("alle ore 12.12 gli studenti di Korce hanno scioperato cantando [...] abbasso il fascismo, viva il comunismo, vogliamo liberare l'Albania. [I carabinieri hanno] fatto subito uso delle armi e disperdendo gli scioperanti. Gli scioperanti hanno avuto 1 morto e più di 20 feriti. Nessuna perdita da parte nostra", pp. 69-70).

Nelle lettere scambiate con la famiglia durante la prigionia emerge invece sopra tutti il tema della reciproca mancanza di notizie che, secondo gli studiosi della storia e della memoria degli internati militari italiani, fu per molti di loro un elemento e una causa di sofferenza quasi pari alle privazioni materiali patite nei lager.

L'assenza di comunicazione con le famiglie emerge anche nel diario compila- 
to nel meno precario contesto albanese e fu all'origine dell'unica nota del maresciallo calabrese realmente intima e privata. Egli, infatti, seppure abituato al contatto con la morte e con le privazioni materiali, non riusciva a vincere la nostalgia per la mancanza della famiglia: "questo suo [della moglie] silenzio ostinato e lungo $\mathrm{mi}$ ha reso irrequieto e ho trascorso le feste natalizie molto disturbato e nervoso. Pazienza!" (p. 72).

Alessio Marzi

\section{Musei}

Gaetano Dato, Redipuglia: il sacrario e la memoria della Grande guerra 19381993, Trieste, Istituto regionale per la storia del movimento di Liberazione nel Friuli Venezia Giulia, 2014, pp. 144, euro 15.

I centomila sepolti nel sacrario militare di Redipuglia, in provincia di Gorizia, fanno di quel sacrario il maggior europeo e uno tra i più imponenti monumenti ai caduti della Grande guerra, non solo in Italia. Il saggio di Gaetano Dato analizza il rapporto tra lo Stato e la memoria pubblica del primo conflitto mondiale nelle sue diverse fasi dal primo dopoguerra agli anni Ottanta, passando per le complesse vicende del "confine orientale" nel secondo dopoguerra.

Redipuglia, uno dei principali luoghi della memoria nazionale, è qui studiato per la sua funzione pedagogica e di autorappresentazione. Il libro, solido nell'impianto teorico e nelle fonti documentarie, si snoda seguendo il processo novecentesco di sacralizzazione della politica, attento al legame fra luoghi di memoria e costruzione/stabilizzazione dell'identità nazionale: Redipuglia appare così un caso di particolare interesse in quanto "archetipo di luogo della memoria italiano" (p. 16). L'autore sistematizza la letteratura precedente sull'argomento e raccorda fonti di diverso livello con uno sguardo di lungo periodo, registrando con precisione conti- nuità e mutamenti del diverso uso pubblico della storia.

Tra retoriche belliciste e dolore per la perdita di una generazione di italiani, la sua memoria della guerra è descritta nei termini di un'esperienza "sacra", secondo logiche e pratiche che avrebbero portato la politica negli anni Trenta a svolgere le funzioni di una religione civile. L'autore insiste sul fatto che la commemorazione dei morti sia stata il fulcro della religione della patria: ciò è particolarmente significativo nel caso del fascismo che sul reducismo e sul culto dei caduti investì politicamente fin dai propri esordi, capitalizzandone la memoria in termini di consenso. Fin dalla fondazione del primo memoriale, antecedente all'attuale, Redipuglia è quindi colto nel suo essere stato un tempio per il mito della nazione, fondato sull'immagine del sacrificio e centrato sulla sua fusione tra il luogo, teatro di combattimenti, e le sepolture dei soldati.

Inaugurato nel 1923 sul vicino Colle sant'Elia, il primitivo cimitero raccoglieva, infatti, i corpi di 463 ufficiali e 30.000 fanti. Progettato dal colonnello Giuseppe Palladini e disegnato da Giannino Antona Traversi (interventista e autore di teatro), fondeva tradizione militare e retorica popolare, iconografia cristiana e simbologia nazionalista. Tra elementi devozionali e i suoi diversi "gironi" concentrici in filo spinato, punteggiati da cimeli bellici ed epigrafi edificanti, il memoriale era caratterizzato dalla mitizzazione dell'esperienza bellica ed era capace di parlare a parenti dei caduti e ai reduci e di richiamare i miti del milite ignoto, dell'"esercito dei morti" e del Risorgimento. Con 200.000 visitatori negli anniversari, era un'“attrazione turistica” (p. 35) per ex combattenti, famiglie, scuole, gite del dopolavoro e punto di riferimento per la riappropriazione simbolica delle terre "redente".

Il sacrario del 1938 mostrò invece le trasformazioni subite dalla religione politica sotto il regime fascista, verso una ritualità dello Stato orientata a trasferire le credenze nel martirio/resurrezione dal pia- 
no personale a quello collettivo. per farlo coincidere con la rigenerazione della "nuova" nazione. Con l'impressionante dimensione monumentale della sua struttura a gradoni aumentò anche il numero dei defunti ospitati fino a oltre 100.000: circa 40.000 nomi sono accompagnati dalla insistita scritta PRESENTE, a rievocare l'appello dei funerali squadristi: ai loculi per i militari si aggiungeva ora anche il sarcofago del Duca d'Aosta, morto nel 1931. La depersonalizzazione massificante della morte rispondeva al concetto totalitario del primato dello Stato sull'individuo e il nuovo assetto inseriva la Grande guerra in una narrazione funzionale alla vocazione imperiale e bellica del fascismo: forse non a caso l'inaugurazione fu connessa al viaggio di Mussolini a Trieste che in Piazza Unità d'Italia annunciava la legislazione razziale.

Negli anni successivi il luogo fu però trascurato da Mussolini e dall'establishment: l'alleanza con la Germania sconsigliava manifestazioni antitedesche mentre il conflitto consegnava la regione all'amministrazione nazista dell'Adriatisches Künstenland. A ciò si deve il paradosso per cui Redipuglia, "tra i massimi templi della religione politica del fascismo, visse i suoi anni più gloriosi nei primi anni della Repubblica" (p. 16), la quale però lo inserì nel proprio progetto di "religione civile moderata e dinamica" insieme nazionale e democratico. Dopo il 1945, Redipuglia fu visto come un simbolo di armonia repubblicana, in continuità con lo Stato liberale e con la Chiesa cattolica e con l'esaltazione dell'unità religiosa, politica e morale degli italiani. Quel dopoguerra vide le commemorazioni più importanti, in particolare nel 1950, anno giubilare, quando 30.000 partecipanti ebbero l'indulgenza plenaria per intercessione papale.

Tra il 1948 e il 1953 il ministro della Difesa Rodolfo Pacciardi intese dare impulso a una religione civile dal sentore mazziniano: il 4 novembre divenne Giorno dell'Unità nazionale, con la Grande guerra a rappresentare una continuità valoriale capace di evocare tanto il Risorgimento quanto la Resistenza e la riconciliazione nazionale dopo la recente guerra civile. La memoria dolorosa della nazione e dei "caduti di tutte le guerre" si saldò alla questione di Trieste, il che fece del sacrario uno snodo centrale della memoria pubblica: una memoria a cui ex partigiani ed ex fascisti opponevano specifiche memorie.

Il libro mostra, infine, come sino agli anni Sessanta-Settanta, in parallelo alla sua dimensione pubblica, Redipuglia vide diminuire le visite e le presenze: una partecipazione sempre più stanca, fino al recente declino, forse il tramonto della precedente rimembranza eroica e militarista della Grande guerra, che ha lasciato oggi il posto al ricordo delle vittime del secondo conflitto mondiale e a ideali di pace e riconciliazione.

Con le eccezioni del presidente della Repubblica Sandro Pertini, ex combattente, e del ministro della Difesa Giovanni Spadolini, cui si deve un tentativo di rilancio d'identità italiana "risorgimentale", retoriche e cerimonie codificate e ripetitive sembrano all'autore aver sancito la fine della centralità del sacrario giuliano e della Grande guerra nel sentire collettivo. Con gli anni Novanta, sui quali si chiude la ricerca di Dato, i linguaggi, i luoghi e le pratiche dell'identità sarebbero diventati altri.

Enrico Manera

Layla Betti, Elena Tonezzer (a cura di), La storia della città. Esperienze di narrazioni e rappresentazioni museali, Trento, Fondazione Museo storico del Trentino, 2015, pp. 149, euro 13.

Il volume riflette sulla definizione e sulla metodologia di realizzazione degli allestimenti museali, permanenti o temporanei, che hanno come obiettivo la narrazione storica delle città, con particolare attenzione all'età contemporanea. Il vo- 
lume è frutto di un'indagine comparativa - curata dalla ricercatrice Layla Betti, che su tale argomento ha lavorato due anni e da Elena Tonezzer, responsabile per la Fondazione committente e editrice delle attività di ricerca e di divulgazione della storia della città — su differenti realtà museali italiane ed europee, con il proposito di proporre in primo luogo uno strumento di discussione e di riflessione sulla sperimentazione dei contenuti culturali e dei metodi di ricerca adottati dai singoli istituti.

La riflessione nasce dalla mission stessa della Fondazione del Museo storico del Trentino: dalle sue caratteristiche originarie, che dal 1823 lo vollero prima $\mathrm{Mu}$ seo del Risorgimento e poi della Prima e Seconda guerra mondiale; dalla collaborazione costante avvenuta fra quel museo e la locale amministrazione comunale, sia in termini di donatore, che di patrocinatore degli allestimenti museali e delle mostre temporanee; infine, dalle finalità principali della stessa Fondazione, ovvero quello di essere un primo esempio di spazio museale di narrazione e di conservazione della storia della città di Trento, con scopi didattici e divulgativi verso la cittadinanza (su questo, si veda il saggio di Elena Tonezzer).

Il momento di confronto fra l'esperienza della Fondazione e quelle delle altre realtà museali italiane e straniere qui prese in esame (fra cui il Museo Alto Garda, il Museo civico di Rovereto, il Museo civico d'arte antica di Torino, il Museo della storia di Bologna e il Museu d'història de Girona, Catalogna, casi di studio presentati nei saggi che compongono il testo) si concentra soprattutto sul rapporto fra l'istituzione cui è stato affidato il compito di conservare e narrare la storia della città e il territorio (e la comunità) che ne risulta al tempo stesso oggetto di studio e soggetto partecipante.

Un secondo oggetto di riflessione del volume è il ruolo della conoscenza e della ricerca nei progetti di raccolta della memoria del territorio. In particolare il libro analizza attorno a quali elementi gli istituti coinvolti abbiano concentrato la propria attenzione, quali risorse essi abbiano inteso come comuni e identitarie e infine verso quali finalità abbiano indirizzato le loro esposizioni.

Infine, il volume si sofferma su come e perché la conoscenza storica relativa alla città e a un territorio possano essere fattori influenti sugli indirizzi programmatici delle politiche pubbliche, specialmente quelle relative al "pluralismo culturale e alle sinergie tra i soggetti che operano nel campo della ricerca storica in città" (così Giuseppe Ferrandi, direttore della Fondazione del Museo storico del Trentino). Ne consegue una riflessione sia sugli strumenti di restituzione dei progetti di ricerca, sia sul target di destinazione delle mostre temporanee e permanenti.

Il volume offre così un quadro assai esemplificativo dell'attività delle singole realtà museali. L'attenzione pare essersi concentrata su alcuni elementi: le missions che si pongono alla base dell'allestimento di un museo della città; gli obiettivi che s'intendono raggiungere; il target di destinazione del progetto museale; il metodo di allestimento; le relazioni che si costituiscono con il territorio circostante e gli altri attori sociali e politici presenti su di esso, compresa la cittadinanza e le organizzazioni da essa costituite; infine, il network nel quale si inserisce il museo della città.

Dall'analisi di questi elementi, il volume non intende trarre conclusioni generali e univoche. Nella realizzazione di un museo della città, vi si sostiene, alla fine molto dipende dal know-how del territorio nel quale e per il quale esso è allestito da parte dei curatori e degli studiosi.

Non esisterebbe allora una formula riproducibile in contesti differenti, ma è il contesto stesso che fornisce gli elementi utili alla realizzazione di un allestimento museale, temporaneo o permanente, che sia soprattutto uno spazio di servizio pensato con e per la cittadinanza.

Stefania Ficacci 


\section{Movimenti e anni Settanta}

LuCa Falciola, Il movimento del 1977 in Italia, Roma, Carocci, 2015, pp. 270, euro 33 .

Luca Falciola con la sua monografia sul 1977 dà un contributo importante al panorama storiografico sugli anni Settanta in generale e offre uno strumento utile e imprescindibile per chiunque voglia approcciarsi, d'ora in avanti, alla comprensione di questo fenomeno tipicamente italiano. Interpretato sia come movimento di protesta che come anno eponimo - ma comunque come "singolo aggregato" - , il 1977 è raccontato a partire da una ricerca empirica meticolosa che, come esplicitato dall'autore, è scaturita dal bisogno di svincolare l'analisi di questo crocevia storico dall'"eccesso di estetica", dalla "ipertrofia della memorialistica", dalla "inflazione interpretativa" e della letteratura secondaria (pp. 16-17).

Sebbene le fonti primarie prendano di rado la parola nel testo, tuttavia ne costituiscono evidentemente la salda e preziosa impalcatura. Il lavoro, infatti, è costruito a partire dall'intreccio di periodici e fogli del movimento (oggi conservati, in gran parte, presso la Beinecke Library della Yale University); volantini e documenti originali depositati presso archivi pubblici; e materiale proveniente da collezioni private (come per esempio quella di Pablo Echaurren). A questo impianto Falciola ha aggiunto lo spoglio del "Corriere della sera", utilizzato per condurre un'analisi quantitativa degli eventi di protesta che, tra azioni pacifiche e violente, hanno interessato soprattutto il centro e il nord Italia (in primo luogo Roma, a seguire Torino, Bologna e Milano) e in misura minore l'Italia meridionale.

Per comprendere il significato di questo ciclo di contestazione di massa che ha preso le distanze dal Sessantotto e si è opposto fieramente (oltre che alla Democrazia cristiana) al Pci, al sindacato e ai gruppi della nuova sinistra, l'autore ha prestato molta cura alla sua contestualizzazione.
I primi due capitoli sono dedicati, infatti, alla situazione politica ed economica italiana e internazionale: in La crisi della società del lavoro è affrontato il tema della disoccupazione giovanile (con cui l'Italia ottenne il primato tra i paesi della Cee) e quello della "disoccupazione intellettuale", fenomeno di cui si iniziò a parlare proprio nel 1976; nel capitolo La crisi di fiducia nella politica, invece, si cercano le origini della sfiducia nei confronti della classe governativa, della democrazia parlamentare e del sistema politico che, gravemente inficiato dal malcostume politico e da clamorosi scandali, iniziava ad apparire irrimediabilmente bloccato.

Nel terzo capitolo (per alcuni versi il più interessante, ma forse anche il meno organico), la fase di incubazione del movimento è descritta come frutto di una vera e propria rivoluzione culturale. Approfondendo i contributi di femminismo e controcultura, Falciola descrive (in alcuni punti con un eccesso di schematicità e genericità) i paradigmi culturali che si affermarono nel momento in cui la sinistra radicale smise di essere un punto di riferimento, affossata alle elezioni del 20 giugno 1976. Essa, infatti, come messo in luce dall'autore, divenne il bersaglio di critiche radicali e sostanziali provenienti dall'ala libertaria, dai giovani e dalle donne che ne denunciavano il leaderismo, il partitismo e la riduzione del personale a "intimismo piccolo-borghese"; e dall'Autonomia operaia, che le contestava derive riformistiche. In questo affresco nel quale interagiscono attori politici e riferimenti culturali nuovi, trovano spazio anche i gruppi postsituazionisti e, soprattutto, il proletariato giovanile. Dopo la descrizione delle varie forme di protesta tipiche di quello che si presentò come il nuovo soggetto rivoluzionario - dalle occupazioni di spazi da autogestire, alle autoriduzioni, dai festival musicali agli espropri proletari in nome del diritto al lusso - , il terzo capitolo prosegue addentrandosi ulteriormente nelle matrici culturali del 1977. Allo sbiadire della stella del comunismo in- 
ternazionale, l'autore contrappone la luce di tre stelle polari: Michel Foucault; Gilles Deleuze e Félix Guattari con l'antipsichiatria (e quindi anche David Cooper); Agnes Heller con la sua teoria dei bisogni. Questo viaggio tra i nuovi classici della cultura rivoluzionaria si conclude con la descrizione di due forme di espressione e di comunicazione tipiche del movimento del 1977 (la rivista "A/traverso", voce dell'omonimo collettivo bolognese; le radio libere, espressione di un "inedito attivismo"); e con il racconto della vicenda dell'Autonomia organizzata, simbolo della "resilienza del politico".

Il quarto capitolo entra nel vivo della contestazione facendo parlare "con disperazione e rabbia" il movimento sui suoi temi più cari: l'università; la crisi economica, la richiesta di lavoro e il contestuale rifiuto del lavoro; l'ecologia e l'ambientalismo; la ristrutturazione produttiva e il ruolo della classe operaia. L'approfondimento della contrapposizione alla figura dell'operaio organizzato del movimento del 1977 permette all'autore sia di sottolineare la sua essenza giovanile e non studentesca, mettendo in luce le discontinuità rispetto al movimento di nove anni prima, sia di introdurre l'ultimo tema di questo quarto capitolo: il rapporto con il Pci.

Nella sezione "La rivoluzione" i nuovi paradigmi culturali anticipati nel terzo capitolo vengono seguiti nella nuova forma che assunsero con la diffusione dei temi legati alla sfera personale e alla sessualità, con l'affermazione di un registro antipolitico radicale, con la promozione del misticismo e con la nascita di fenomeni peculiari ed emblematici del 1977 come quello degli indiani metropolitani. Con un occhio sempre rivolto al Sessantotto, Falciola cerca di sciogliere il rapporto del movimento con alcune parole chiave - rivoluzione, potere, politica - per poi concludere il lavoro soffermandosi sulla repressione del movimento (osservata con un duplice prospettiva, interna ed esterna al tempo stesso) e sulla violenza politica, distinta nella sua duplice forma (di massa e di gruppi clandestini). Estrema opposizione di una "avanguardia di massa" a un potere considerato pervasivo e onnipresente, l'escalation della violenza è, nell'interpretazione dell'autore, ciò che avrebbe fatto del 1977 un'ultima rivoluzione politica: un "rito di passaggio violento verso gli anni del riflusso" (p. 254).

Paola Stelliferi

PaOla Stelliferi, Il femminismo a Roma negli anni Settanta. Percorsi, esperienze e memorie dei Collettivi di quartiere, Bologna, Bononia University Press, 2015, pp. 224, euro 25.

Il femminismo romano, cui Paola Stelliferi dedica questa ricerca, è stato un fenonemo particolarmente complesso, difficile da mappare, analizzare e interpretare. "Associazioni, redazioni, gruppi culturali e collettivi, molti dei quali identificati con il nome di un quartiere o di un'area della Capitale. Borgata Romanina, Centocelle, Montesacro, Monteverde, Ostiense, Tor Fiscale, Trastevere... quasi ogni zona della città, più o meno periferica, più o meno popolare, sembrava aver dato vita a un collettivo femminista" (pp. 1-2). Nel tentativo di dare ordine a uno scenario "magmatico e composito", l'autrice divide il volume in due parti. La prima, più tradizionale, narra cronologicamente l'irrompere del femminismo a Roma nel corso degli anni Settanta del Novecento e la nascita dei cosiddetti "collettivi centrali", sorti intorno a interessi specifici o alla pratica del separatismo fino all'occupazione di palazzo Nardini, in via del governo Vecchio nel 1976.

Una dimostrazione, quest'ultima, di autorevolezza e di organizzazione da parte della rete dei collettivi romani che però agiva in un equilibrio sempre precario, "in bilico costante tra la riformulazione e l'implosione" (p. 66) tanto per la molteplicità di pratiche e approcci teorici, quanto per le difficoltà esistenziali e politiche delle donne che sperimentavano una doppia 
militanza, nel femminismo e nei gruppi rivoluzionari o nei partiti, spesso sfociata in dolorosi abbandoni.

A ogni modo, il neofemminismo è, ormai, un fenomeno politico di massa. Nella seconda parte del volume, dunque, il focus si sposta sulle periferie e i "collettivi di quartiere" diventano il cuore della ricerca. In particolare, quelli di quattro aree della città: Magliana, Appio-Tuscolano, Casal Bruciato e Testaccio. Ma quello che Stelliferi compie non è un mero censimento. Al contrario, è il tentativo di proporre nuove prospettive di metodo e d'interpretazione agli studi sui femminismi proprio attraverso la dialettica tra centro e periferia, autentico nodo cruciale e problematico di questa ricerca. Possediamo una documentazione e un'esperienza visiva — grazie alle fotografie di Paola Agosti, Silvestre Loconsolo, Tano D'Amico - di quanto e di come il neofemminismo abbia attraversato le piazze e le vie delle città, occupato stabili vuoti trasformandoli in luoghi di socialità, elaborazione e spesso di cura ma anche di come abbia agito nelle periferie, nei luoghi di lavoro. Tuttavia il concreto spazio d'esperienza e di presenza del femminismo non è stato mai sufficientemente indagato. Uno spazio qui interpretato in modo appropriato sia come assetto urbano, ma anche come interazione (riuscita o fallita), come relazione, non solo politica, con le dinamiche sociali dei luoghi. È una proposta di messa a fuoco delle connessioni, delle stratificazioni urbane, politiche e umane che decostruisce l'idea della periferia come marginale. Ma ridisegna anche alcune rilevanze della storia politica dell'Italia repubblicana, come ricorda una delle intervistate a proposito del referendum del 1981 concernente l'abrogazione della legge 194 sull'interruzione volontaria della gravidanza: "Io mi ricordo che raccolsi le firme davanti alla Fatme (una delle principali fabbriche di Roma n.d.r.) [...] ma ne raccolsi tantissime, tutte! [...] adesso quando a volte il Partito radicale rivendica come sua questa battaglia... dimentica sempre questa diffusione del movimento femmi- nista nei quartieri, nelle città di tutta Italia che erano invece la forza per la legge sull'aborto e sul divorzio" (p. 140).

L'autrice opera questa messa a fuoco attraverso l'uso di fonti quasi esclusivamente orali. Considerarla una scelta obbligata da una carenza di fonti documentarie non le renderebbe ragione. Appare, invece, una scelta consapevole e adatta per indagare un fenomeno particolarmente frammentato che aveva fatto della "soggettività, dell'autorappresentazione e della narrazione dei vissuti personali il principale strumento di liberazione individuale e collettiva" (p. 4). La memoria è strumento ma, in questo caso, è soprattutto il principale oggetto da indagare.

Questo rappresenta uno scarto rilevante perché è un'ulteriore decisa rottura con la cosiddetta "memoria possessiva" secondo l'elaborazione di Peter Braunstein che Emmanuel Betta e Enrica Capussotti hanno applicato anche al femminismo, parlando di un' "egemonia della testimonianza" che limiterebbe la possibilità per i soggetti che non hanno preo parte a quell'esperienza di partecipare all'interpretazione (E. Betta, E. Capussotti, "Il buono, il brutto, il cattivo": l'epica dei movimenti tra storia e memoria in "Genesis. Rivista della Società Italiana delle Storiche", n. III/1, 2004, pp. 118).

Il volume sviluppa a un quadro complesso, contraddittorio e per niente idealizzato che talvolta smentisce anche alcune ipotesi di partenza dell'autrice, per esempio quella secondo cui "a Roma il movimento femminista riuscì a essere nella prassi, e non solo nella teoria, trasversale a tutte le classi sociali". Infatti, i collettivi che si formarono nelle aree dove risiedeva il proletariato urbano furono avviati da giovani donne appartenenti al ceto medio, spesso studentesse universitarie, soprattutto militanti della sinistra rivoluzionaria. Almeno nelle aree analizzate in questa ricerca emerge come i collettivi e i consultori autogestiti dei quartieri popolari furono "il terreno in cui ragazze in gran parte borghesi e, soprattutto, omogenee tra lo- 
ro dal punto di vista culturale, tentarono di incontrarsi con le donne considerate 'più oppresse' seguendo, quasi sempre, i percorsi già tracciati nelle periferie dalle organizzazioni della nuova sinistra, tra cui Avanguardia operaia, Lotta continua e Manifesto" (p. 6).

Non viene nascosta da un verso una visione eroica/esotica e mitizzata delle donne del proletariato urbano (come degli operai), dall'altra un'autentica alterità: “ci avvertivano come studentesse privilegiate, altre da loro. Di fatto così era", ricorda una delle intervistate (p. 135). È una questione di grande rilievo perché suggerisce che un approccio intersezionale nell'analisi storica dei movimenti, e dei movimenti femministi in particolare, andrebbe definitivamente recepito.

Alessandra Gissi

\section{Economie italiane}

Emanuele Felice, Ascesa e declino. Storia economica d'Italia, Bologna, il Mulino, 2015, pp. 385, euro 18.

Questo libro è molte cose insieme e meritano tutte pari attenzioni.

È una sintesi certamente attesa della storia economica di questo paese, una sintesi che considera nuove ipotesi storiografiche e riconsidera vecchie visioni (Rostow, Romeo, Gerschenkon, Bonelli e Cafagna) alla luce di nuove evidenze quantitative. Attenta alla collocazione dell'Italia nell'economia mondiale, grazie al suo approccio comparativo, salda strettamente il caso italiano agli studi e al dibattito internazionali. È una sintesi che era attesa perché fa il punto sulle indagini degli ultimi decenni riguardo all'andamento delle principali grandezze macroeconomiche dall'Unità a oggi (il volume è corredato anche di un'appendice online). Lo fa a partire dal dato principale, ossia la ricostruzione di lungo periodo del prodotto interno lordo a prezzi coerenti e costanti, una ricostruzio- ne a cui hanno lavorato Stefano Fenoaltea per l'industria, Giovanni Federico per l'agricoltura, Patrizia Battilani e Vera Zamagni per i servizi e molti altri studiosi (tra cui l'autore) per i singoli periodi. Un'ulteriore spinta è poi arrivata dalle celebrazioni per i centocinquanta anni dell'Unità e dal lavoro di raccordo delle singole serie storiche promosso dalla Banca d'Italia con l'Istat e con diverse università italiane, un lavoro che ha depositato i suoi risultati in un Oxford Handbook of the Italian Economy since the Unification (Oxford University Press, 2013; tr. it. Marsilio, 2013), curato da Gianni Toniolo, con quasi cinquanta contributori per più di venti saggi, molti dei quali scritti da studiosi italiani e anglosassoni insieme.

Il volume di Emanuele Felice quindi prende avvio da un quadro quantitativo preciso e condiviso "che potremmo chiamare "la nuova storia economica d'Italia" (p. 54) e che consente di osservare più finemente dinamica del reddito, trasformazioni sociali, povertà e disuguaglianze, misure e dimensioni del benessere (misure antropometriche, salute, lavoro minorile, istruzione, qualità della vita, studiate in dettaglio da Giovanni Vecchi, In ricchezza $e$ in povertà, il Mulino, 2011), divari territoriali (un problema strutturale rimesso a fuoco in termini anche quantitativi da Vittorio Daniele e Paolo Malanima, Il divario Nord-Sud in Italia 1861-2011 e poi nuovamente sistematizzato dallo stesso Emanuele Felice, Perché il sud è rimasto indietro, il Mulino, 2013).

È la prima sintesi che esce dopo quella che Vera Zamagni aveva proposto nel 1990 sotto il titolo Dalla periferia al centro che suggellava una fase di ascesa, quindi una fase in cui l'economia italiana raggiungeva e superava quella britannica. In particolare, è la prima sintesi che appare dopo che la recessione innescata dalla crisi finanziaria globale del 2007-2008 ha esasperato gli elementi di affanno che l'economia italiana mostra dall'apertura degli anni Novanta, quando si apre "una fase di palese incontestabile declino (i cui pro- 
dromi per la verità si possono cogliere già sul finire dell'età dell'oro)" (p. 60).

È un'opera di divulgazione alta, intenzionata a offrire strumenti interpretativi sul presente a un ampio pubblico, oltre che agli studiosi e agli studenti che si avvicinano alla storia economica italiana nei loro corsi universitari. È il contributo di uno studioso anagraficamente giovane, scientificamente maturo (è certamente inusuale in Italia che un ricercatore si misuri così presto con un'opera di questo respiro) che accanto all'attività accademica coltiva quella di editorialista.

È anche il contributo di uno studioso organico a una precisa comunità interpretativa italiana, europea e nordamericana e ai suoi specifici sentieri, il quale riflette non solo sugli esiti ma anche sul metodo di questa nuova storia economica. Si tratta essenzialmente di una storia macroeconomica la cui direzione tende ad allontanarsi sempre più sia dalla business history, sia più in generale dalla ricerca qualitativa e dalla ricerca in archivio per avvicinarsi invece a quello della applied economics. Una divaricazione che Emanuele Felice constata, ma che giudica anche come una perdita per la disciplina.

L'approccio del libro di Emanuele Felice è interessante per almeno due ragioni (di cui la prima è forse più vistosa, ma la seconda più rilevante): l'attenzione al trattamento statistico-econometrico di una grande mole di dati quantitativi e la proposta modellizzante. Nell'arco degli ultimi decenni l'accezione del termine economia, infatti, si è allargata molto al di là di quella tradizionale, che corrispondeva a un dominio di studio da un punto di vista sostantivo (la scienza sociale che si occupa di capire come funziona l'economia reale e finanziaria); un'accezione diversa (e oggi decisamente mainstream) pone invece l'enfasi sul metodo: l'economia come disciplina è oggi associata più alla modellizzazione formale (spesso matematica, il che non coincide affatto con quantitativa) che non a particolari ipotesi sul funziona- mento dell'economia reale e finanziaria; il suo dominio di interesse si è imperialisticamente esteso, e in particolare nell'area della political economy (cfr. a questo proposito le considerazioni di Dani Rodrik, Economic Rules, Oxford, University Press, 2015). Emanuele Felice attinge a due dei contributi che in questo campo hanno probabilmente avuto più influenza nei tempi recenti e più fascinazione per gli storici: da una lato a Perché le nazioni falliscono di Daron Acemoglu e James Robinson (Il Saggiatore, 2013, ed. or. 2012) e alla loro distinzione fra "istituzioni estrattive" (finalizzate a estrarre una rendita per una ristretta cerchia di privilegio e destinate ad avere effetti negativi sulla crescita) e "istituzioni inclusive" (che includono le fasce più ampie di popolazione nel processo di sviluppo economico); dall'altro al lavoro di Douglass North, John Wallis e Barry Weingast, Violenza e ordini sociali (il Mulino, 2012, ed. or. 2009.) che distingue invece fra ordini statuali "ad accesso limitato" (a loro volta distinti in "fragile", "di base", "maturo") e ordini "ad accesso aperto".

Sono esattamente le istituzioni politiche italiane e il ruolo giocato dalla classe dirigente nazionale e locale nei diversi periodi a fare da perno al volume di Emanuele Felice. La struttura del libro è tradizionale nella sua parte centrale, in cui, dopo una carrellata dalla storia romana all'Unificazione, quattro capitoli scandiscono una periodizzazione consolidata dall'età liberale all'ultima globalizzazione. Non lo è invece nei due capitoli che si concentrano sulla tesi interpretativa: questa è anticipata nel secondo, che ne espone gli impianti teorici, e viene poi sintetizzata nell'ultimo, in uno schema che stilizza la dinamica delle variabili che determinano il cambiamento economico (p. 347): assetto socio-istituzionale, contesto internazionale (unica variabile considerata esogena), risorse e variabili di lungo periodo. L'Italia ha conosciuto crescita della "ricchezza della nazione" nelle fasi in cui si è data istituzioni inclusive e un ordine aperto (sia al com- 
mercio internazionale sia ai diversi ceti sociali); ha conosciuto declino quando la situazione si è rovesciata, dopo gli anni Settanta, quando, prima lentamente e negli anni Novanta per strappi, si è barattato l'allargamento del consenso con la mancata modernizzazione delle istituzioni.

Roberta Garruccio

Corrado Scibilia, L'olimpiade economica. Storia del Comitato nazionale per l'indipendenza economica (1936-1937), prefazione di Paul Corner, Milano, FrancoAngeli, 2015, pp. 172, euro 23.

Il libro ricostruisce la breve storia del Comitato nazionale per l'indipendenza economica (Cnie), un organismo creato dal partito nazionale fascista nell'ambito della politica autarchica con lo scopo di ridurre la dipendenza dell'Italia dall'importazione di materie prime. Costituito nella primavera 1936, come evoluzione del Comitato per la resistenza alle sanzioni, creato pochi mesi prima, il Cnie avviò da subito alcuni progetti: costituì due centri di ricerca, uno sul settore tessile a Milano e l'altro sul settore minerario a L'Aquila (città natale e feudo politico di Adelchi Serena, il maggiore sostenitore del Comitato); inoltre, indisse il primo concorso nazionale per le materie prime fondamentali (un" "olimpiade economica", secondo la propaganda), per premiare le migliori ricerche sullo sfruttamento economico delle materie prime italiane.

Ad animare quelle iniziative furono due figure di secondo piano dello stato fascista: Aldo Aytano e Corrado Petrone. Entrambi con formazione giuridica, alternarono vorticosamente incarichi nell'apparato giudiziario, nei gabinetti ministeriali e nelle amministrazioni parallele, incrociandoli con un'incessante attività pubblicistica e la precoce appartenenza al Pnf, alla perenne ricerca di più solide protezioni e nuovi guadagni. Alla ricostruzione della carriera di queste due figure è opportunamente dedicata una parte consisten- te del libro, necessaria per ricomporre tutti gli elementi connessi alla vicenda del Cnie ma che, al tempo stesso, apre un percorso di analisi parallelo: due studi di caso di tipici esponenti delle seconde linee del regime, capaci di illustrare con efficacia il ruolo giocato da cooptazione, favoritismi e clientelismo nella formazione e selezione della classe dirigente fascista.

Il Cnie costituì per Aytano e Petrone un'occasione per acquisire visibilità e nuove entrature nell'establishment. Nell'attività del Comitato seppero coinvolgere Pietro Badoglio, cui fu assegnato l'“alto patronato" dell'iniziativa in nome del necessario legame tra industria e difesa, e alcuni autorevoli esponenti del mondo economico, tra cui spiccano i nomi di Guido Donegani e Senatore Borletti: il primo e i secondi, tuttavia, più interessati a cercarvi occasioni per assecondare i propri progetti e interessi che al reale successo dell'ente. Fu invece il coinvolgimento di Adelchi Serena segretario ad interim del Pnf nei mesi della guerra d'Etiopia, quando Starace fu inviato al fronte - a risultare realmente decisivo. Serena vide infatti nel progetto di Aytano e Petrone l'occasione per ampliare ruoli e attribuzioni del partito, ponendolo "al centro della rete di relazioni tra ricerca, industria, militari e politica" (p. 15).

Nelle intenzioni iniziali, il Comitato avrebbe dovuto assurgere a vero e proprio "stato maggiore dell'economia" (una qualifica per la verità attribuita anche ad altri organismi economici di quegli anni, a dimostrazione della pervasiva militarizzazione che investì l'intervento pubblico durante gli anni Trenta). Le roboanti formule propagandistiche ottennero però, in questo caso, ben pochi riscontri con la realtà. Il Cnie ebbe infatti vita stentata e brevissima. Già dopo i primi mesi fu svuotato di poteri e funzioni, e venne definitivamente sciolto nell'estate 1937, a poco più di un anno dalla sua fondazione; quando, tra l'altro, con il suo ritorno in Italia, Starace aveva assunto nuovamente la guida del Pnf. I progetti avviati e in corso furono in seguito attribuiti al Cnr, presieduto proprio da Badoglio. 
Scibilia ripercorre minuziosamente, con grande abbondanza di dettagli, la storia del Cnie. Ne risulta un'analisi al microscopio, che dà conto di ogni passaggio dell'iter costitutivo del Comitato e di ogni rivolo della sua attività, stringendo però il campo d'osservazione. Rimangono sullo sfondo il contesto istituzionale e politico, interno e internazionale, della politica autarchica, così come gli antecedenti e gli sviluppi dell'attività del Comitato. È, evidentemente, una precisa scelta dell'autore, che privilegia un'analisi molto ravvicinata delle numerosi fonti (tra le quali le carte di Adelchi Serena, non ancora depositate presso un'istituzione archivistica) tralasciando invece di confrontarsi con la storiografia sull'economia dell'Italia fascista e, in particolare, con quella sulle diverse diramazioni dell'autarchia.

Eppure, parallelamente al Cnie, nel breve periodo in cui questo fu in attività, agirono altri soggetti, che ne contendevano ruoli e funzioni e raggiunsero risultati ben più rilevanti: l'Iri, il Cnr, le corporazioni, la sovrintendenza, poi sottosegretariato e ministero per gli scambi e valute, senza dimenticare le funzioni istruttorie e di regolazione assunte dalle associazioni imprenditoriali. Si trattava di organismi molto più solidi e qualificati, sia per il profilo istituzionale sia per le competenze tecniche che erano in grado di mobilitare. Inserita in questa trama di poteri e di apparati, l'iniziativa di Aytano e Petrone appare evidentemente velleitaria, se non sin da subito destinata al fallimento. Non per questo però la sua ricostruzione è priva di motivi di interesse. La ricerca al microscopio di Scibilia, infatti, nella minuziosità del racconto mostra in filigrana i rimandi ad almeno due nodi interpretativi di indubbia rilevanza.

Il primo, vi accenna l'autore nell'introduzione, è l'incapacità del Pnf di assumere un ruolo significativo nell'ambito delle politiche economiche. La vicenda del Cnie è in questo senso emblematica, perché si collocò in un momento, quello della svolta autarchica della metà degli anni Trenta, in cui il rapporto con il mondo economico e con la dirigenza dei grandi enti sembrò diventare più favorevole alla politica. Emersero allora limiti "di sistema" (il ruolo di organizzatore della mobilitazione e di pedagogo assegnata al Pnf, escluso invece da ogni funzione di governo), ma anche di uomini. A differenza dei coevi regimi a partito unico, in Italia mancò un Göring o un Trotckij, cioè dirigenti politici di primissimo piano e della prima ora capaci di imporre un proprio indirizzo strategico o di guidare organi dotati di potere decisionale.

Il secondo è relativo alla questione della preparazione bellica. Come osserva Paul Corner nella stimolante prefazione, "il volume serve anche - e forse soprattutto - a rendere chiaro quanto l'idea di guerra fosse centrale nel pensiero e nella politica del fascismo" (p. 10). E serve anche a illustrare quanto la convergenza tra esigenze militari e apparato produttivo sia avvenuta in maniera tardiva e contraddittoria, schiacciata dai limiti strutturali dell'economia nazionale (carenze di materie prime, fonti energetiche, capitali e tecnologie) ma anche dall'irrisolto policentrismo dello Stato fascista, in cui rilevanti furono i personalismi e la concorrenza tra apparati. Il Cnie nacque perché le ambizioni di Aytano e Petrone incontrarono, per un breve momento, i disegni e gli interessi di Serena. Ma dovettero soccombere a soggetti (in primo luogo Badoglio) i cui disegni, interessi e poteri di condizionamento furono più forti.

Alessio Gagliardi

\section{Ai confini d'Italia}

Diego D'Amelio, Andrea Di Michele, Giorgio Mezzalira, La difesa dell'italianità. L'Ufficio per le zone di confine a Bolzano, Trento e Trieste (1945-1954), Bologna, il Mulino, 2015, pp. 604, euro 42.

Trasferito all'Ufficio per le zone di confine. Questa frase, dattiloscritta su di un foglietto bianco infilato in un faldone re- 
golarmente vuoto, è stata per anni fedele e frustrante compagna degli studiosi che desideravano cimentarsi con le vicende delle regioni di frontiera italiane nel secondo dopoguerra, sia che ci si volgesse a nord, al Trentino Alto Adige, che a oriente, alla Venezia Giulia. La dimensione diplomatica del problema era assai più facile da ricostruire, vista l'abbondanza delle fonti italiane, britanniche, americane e austriache, ma quali politiche avesse seguito il nuovo Stato italiano da poco uscito dalla guerra e affacciatosi alla democrazia, per gestire la crisi nazionale apertasi in due aree che avevano costituito il pegno della vittoria nella grande guerra e sulla quali nei precedenti decenni enorme era stato l'investimento simbolico, questo largamente sfuggiva, perché nell'ombra rimaneva avvolta la storia di quella che era stata la vera cabina di regia di quelle politiche, vale a dire l'Ufficio per le zone di confine, costituito nel 1947 presso la Presidenza del Consiglio e affidato alle cure dell'allora giovanissimo sottosegretario Giulio Andreotti. La pluridecennale ricerca della documentazione scomparsa costituisce già un affascinante capitolo di storia archivistica, ma non è che la premessa del corposo volume, frutto del lavoro di un vasto gruppo internazionale di ricercatori, che si sono assunti il compito di distillare i risultati della prima stagione sistematica di indagini sui fondi dell'Uzc, resi disponibili a partire dal 2008 presso l'Archivio della Presidenza del Consiglio, che ne ha curato il riordino.

Naturalmente, il volume ha inizio con una puntuale ricostruzione della parabola dell'Uzc, dalle ragioni che ne consigliarono l'istituzione — raccogliendo l'eredità per un verso dell'Ufficio Alto Adige, per l'altro dell'Ufficio Venezia Giulia, costituiti nel 1946 presso il ministero dell'Interno - fino al suo scioglimento nell'estate del 1954, quando ormai imminente appariva il ritorno di Trieste all'amministrazione italiana, mentre si apriva una nuova stagione di rapporti fra il governo di Roma e i rappresentanti della componen- te tedescofona in Alto Adige. Dalle pagine di Andrea Di Michele emerge la centralità del prefetto Silvio Innocenti, considerato all'epoca uno dei più brillanti funzionari dell'amministrazione italiana e una delle figure chiave per intendere la transizione dei vertici della burocrazia italiana dal regime fascista alla stato democratico passando attraverso l'esperienza del regno del Sud, della cui organizzazione amministrativa Innocenti fu protagonista. Accanto a lui, si delinea una scelta pattuglia di "specialisti" delle aree di confine, capaci di giocare le loro particolari competenze all'interno di contesti istituzionali assai diversi, come quel triestino Edoardo Bisia, che si formò nell'amministrazione austroungarica, per poi passare a quella italiana, liberale e fascista, fino a diventare viceprefetto della provincia di Lubiana costituita nel 1941 e concludere la carriera come primo commissario del Governo nel Trentino Alto Adige.

Seguono poi le due parti dedicate rispettivamente alle vicende del Trentino Alto Adige e della Venezia Giulia. I temi sono numerosissimi. Per il Trentino Alto Adige: l'elaborazione dello statuto di autonomia, complicato dall'esistenza non solo di una "questione altoatesina" da risolvere nell'ambito dell'accordo De Gasperi-Gruber, ma anche di una "questione trentina", dove alla richiesta di ampie forme di autonomia regionale si accompagnava il rifiuto di un'autonomia particolare per la provincia di Bolzano; il ruolo del problema sudtirolese nei rapporti italo-austriaci fino agli anni Sessanta; la funzione dei partiti politici, centrato sulla tesi che la soluzione della questione altoatesina si avviò (ma ci mise un bel po' ad arrivare) nel momento in cui il problema del confine del Brennero si trasformò da un conflitto di identità a un conflitto di interessi; l'immigrazione italiana nella provincia di Bolzano, che ai sudtirolesi (esagerando un tantino) fece temere di venir travolti dal punto di vista etnico; il nodo del ritorno degli optanti che nel 1938 avevano scelto il Terzo Reich e il cui rientro costituiva uno dei pilastri de- 
gli accordi De Gasperi-Gruber, ma che innescò una selva di problemi, dal riacquisto della cittadinanza italiana, al recupero delle terre, che nel frattempo erano state affidate all'Ente nazionale per le Tre Venezie; le strategie di "propaganda dell'italianità" nella provincia di Bolzano, giocate su di una molteplicità di livelli e fra le quali probabilmente la più efficace fu costituita dai "piani campanile", cioè il sostegno alla creazioni di istituzione ecclesiastiche (parrocchie, oratori, centri sociali, ecc.) per il gruppo italiano in Alto Adige; infine, un focus specifico sul Trentino, da un duplice punto di vista: quello dell'identità di confine dal nesso asburgico all'autonomia regionale e quello della percezione, tutt'altro che lineare (italiani o tirolesi?) dei trentini visti da Roma.

Per la Venezia Giulia, dopo un excursus sui rapporti fra Roma e Belgrado nel complicato dopoguerra adriatico, ecco una serie di contributi volti a esplorare il ruolo del confine nella costruzione antagonista delle identità nazionali italiana e slovena. Al riguardo, si potrebbe forse arricchire l'analisi considerando la funzione legittimante svolta dalla "questione di Trieste" per le forze politiche di governo italiane: fortemente selettiva nel dopoguerra, perché il Pci — stretto fra troppe contraddizioni - non riuscì a goderne ed anzi ne scapitò; ripresa dopo il 1989 proprio dagli ex comunisti, probabilmente divenuti consapevoli anche oltremisura degli errori commessi. Vi è poi una parte assai ricca dedicata alle strategie politiche e propagandistiche messe in atto dall'Uzc a Trieste, dove a risaltare sono da un lato l'enormità dell'impegno finanziario, dall'altro la dialettica tra l'Ufficio e le forze politiche locali pro Italia, che dal sostegno di Roma dipendevano totalmente, ma non sempre ne condividevano le scelte, specie in riferimento alla disinvoltura mostrata da Innocenti nell'utilizzo di frange estremiste neofasciste. Altrettanta attenzione il volume dedica alle forze avverse all'Italia, sia ricostruendo dall'interno l'azione delle componenti pro Jugoslavia, che analizzando lo sguardo attraverso il quale le autorità italiane osservarono sloveni, comunisti e indipendentisti, anche dopo il ritorno dell'Italia a Trieste. Gli ultimi saggi sono dedicati all'Istria, vale a dire al Cln dell'Istria - cui venne affidato il compito di sostenere le comunità italiane residenti nella zona sotto controllo iugoslavo - e allo sgombero degli italiani da Pola, pagina ovviamente drammatica sotto il profilo nazionale e umano ma anche successo dal punto di vista organizzativo.

Infine, il contributo di Diego D'Amelio, Frontiere in transizione. Il lungo dopoguerra dei confini italiani fra eredità, emergenze e distensioni, si propone come riflessione conclusiva dell'intero volume, esplorando a fondo la prova fornita dallo stato repubblicano di fonte a una crisi densa d'implicazione politiche e simboliche. In tal modo, l'analisi del caso di studio costituito dall'Uzc s'inserisce come un tassello prezioso negli studi sulla transizione del sistema politico e dell'apparato burocratico italiani dopo il tornante del 1945, consentendo di mettere meglio a fuoco l'andamento non lineare dei processi di democratizzazione, di creazione del consenso e di riedificazione dell'idea di nazione.

Raul Pupo

Luigi Blanco (a cura di), Ai confini dell'Unità d'Italia. Territorio, amministrazione, opinione pubblica, Trento, Fondazione Museo storico del Trentino, 2015, pp. 607, euro 25 .

Il volume racchiude gli atti del convegno promosso dalla fondazione Museo storico trentino e dall'Università di Trento in occasione del $150^{\circ}$ anniversario dell'Unità d'Italia. Per quanto apparentemente dedicato all'avvio della storia dell'Italia unita, e rivolto ai soli risorgimentisti e ottocentisti cultori di storia delle istituzioni, in realtà una sua lettura appare importante anche per un novecentista. Inoltre, il nesso accentramento-decentramento rimane co- 
stitutivo della contemporaneistica italiana, da Romeo e Ragionieri e Pavone - solo per citare alcuni dei più importanti studiosi - sino a oggi.

L'idea di fondo del volume è quella di guardare al processo di costruzione dello Stato a partire dai confini, dalle periferie che in un determinato momento hanno iniziato a far parte del Regno d'Italia. Tale impostazione consente di avere uno spaccato per molti versi inedito di quel processo. Come spiega Blanco nell'introduzione, la geografia - non sempre presente come dovrebbe negli studi storici - fornisce invece un solido ancoraggio al discorso politico e alla costruzione della nazione. Negli anni del Risorgimento e dell'unificazione era forte l'immagine di un'azione politica che portava a far coincidere i confini politici con quei confini naturali, che in Italia risultavano in genere esser molto bene delineati. Negli scritti dei principali uomini politici dell'epoca, primo fra tutti Giuseppe Mazzini, erano forti le argomentazioni di tipo geopolitico.

Il libro è suddiviso in tre parti. Nella prima si analizzano le scelte politiche della classe di governo e le tradizioni amministrative degli stati preunitari. Luca Mannori indaga sulla prospettiva del federalismo che a lungo era stata accarezzata nel periodo risorgimentale. Il modello amministrativo federale si rivelò assai difficile da perseguire per via della fragilità politica italiana. La molteplicità di situazioni politiche e amministrative che caratterizzavano la penisola è ben presente nel percorso di applicazione dello Statuto nelle nuove province del Regno d'Italia. Quella difficile sfida, per la classe dirigente dell'epoca, è ripercorsa da Gianna Manca prestando attenzione ai diversi risvolti giuridici che si incontravano nei territori in corso di annessione. Francesco Bonini, invece, si occupa della centralizzazione amministrativa e dei rapporti con i poteri locali. Le ragioni dell'accentramento e della conservazione del modello amministrativo piemontese furono predominanti. In un'Italia che si caratterizzava per la forte in- stabilità degli assetti politici, come ebbe a spiegare il deputato Pellegrino Rossi, era possibile tutto tranne che pensare a cambiare le circoscrizioni territoriali. Osservando le singole realtà territoriali è possibile notare che il cammino di costruzione della nuova realtà statuale risultava difficile, perché complicate erano le consuetudini amministrative che vigevano nelle varie province del Regno. In quest'ottica, Blythe Alice Raviola evidenzia i problemi di transizione vissuti nello spazio sabaudo, Simona Mori si occupa del caso lombardo, Gabriella Santoncini analizza la situazione nelle province pontificie, mentre Renata De Lorenzo quella del Regno delle due Sicilie. Le diverse latitudini del Paese offrono un punto di osservazione fondamentale per comprendere quali delicati problemi istituzionali potessero sorgere negli anni dell'unificazione.

Altro tema approfondito nel convegno è quello della "nazione composita/plurale". Lo studio dei legami di appartenenza (municipali, regionali, statuali) è un'interessante punto di partenza per affrontare i molteplici fattori di condizionamento del nuovo Stato nelle sue fasi iniziali. Roberto Martucci illustra la storia "spezzata" delle due Sicilie durante il regno di Federico II di Borbone, nell'occasione fa luce sulle diverse interpretazioni storiografiche proposte anche dalla più recente letteratura a proposito della modernizzazione del meridione e delle sue condizioni finanziarie. Altri interventi riguardano l'italianizzazione dei territori dello Stato pontificio (Paola Magnarelli), le vicende della Valle d'Aosta (Marco Cuaz) e quelle particolari delle province di Parma e Modena (Elio Tavilla). Inoltre, viene offerto uno spaccato del dibattito sull'identità veneta e nazionale (Roberto Gottardi), nonché sul lungo Risorgimento trentino, che ha trovato il suo momento cruciale negli ultimi due decenni dell'Ottocento (Elena Tonezzer).

La terza parte del libro è dedicata all'unificazione italiana nell'opinione pubblica europea. Lo sguardo francese sull'Italia — proposto da Jean-Yves Frétigné - è 
incentrato soprattutto su due figure centrali del nostro Risorgimento: Giuseppe Mazzini e Giuseppe Garibaldi. Studiando l'immagine del Risorgimento italiano nel mondo germanico Gabriel B. Clemens rappresenta una situazione di grande attenzione per le vicende italiche e per l'opera del conte Cavour, uno statista decisamente di dimensione europea. Il volume si chiude con l'intervento di Stefan Malfér che illustra l'approccio pacato e distanziato avuto durante le guerre del Risorgimento dalla stampa austriaca.

In conclusione, quello curato da Luigi Blanco è un testo complesso che aiuta a comprendere l'effettiva dimensione del lavoro messo in campo dalle classi dirigenti dell'epoca per la realizzazione dell'unificazione nazionale. Al lettore si offre una chiave di lettura certamente importante che permette di cogliere gli elementi di unità e gli elementi di divisione che ancora permanevano nel Paese. Emergono le dimensioni di uno sforzo molto più partecipato e coinvolgente di quanto si sarebbe portati a ritenere ancora oggi a 150 anni da quei giorni.

Daniele Sanna

\section{Eredità materiali della Guerra fredda}

Alberto Mario Carnevale, Eugenio Ferracin, Maurizio Struffi, Cieli fiammeggianti. Dalla Guerra fredda a $\mathrm{Ba}$ se Tuono. L'eco del "Blazing skies" e gli Hercules nucleari, Bassano del Grappa, Itinera Progetti, 2016, pp. 278, euro 19,90.

Non sempre i volumi più importanti, o più significativi di una certa atmosfera $o$ di un progetto culturale sono editi dai più grandi editori. Questo volume, promosso dalla Magnifica comunità (il Comune) di Folgaria, con il patrocinio della Provincia autonoma di Trento e con la collaborazione dell'Aeronautica militare è uno dei casi in cui una piccola, ma affermata, casa editrice locale introduce una questione di rilevanza nazionale.
Parlare di questo volume è anche, e forse soprattutto, parlare dell'iniziativa culturale che esso sottende, e di cui fa parte. Infatti, è stato scritto dal giornalista ("L'Adige", Rai) Maurizio Struffi, dal generale dell'Aeronautica Alberto Mario Carnevale e dall'esperto di elettronica industriale Eugenio Ferracin. Sono fra i promotori di uno straordinario lavoro di recupero, ricostruzione e organizzazione. Il volume intende accompagnare, forse servire da guida e introduzione, all'allestimento che, in una vecchia base Nato dismessa, appunto a Folgaria, in Trentino, è stato ricreato con gli elementi di fondo di una delle varie istallazioni che nel periodo della Guerra fredda rappresentavano l'ossatura del sistema militare di reciproca sorveglianza e minaccia delle due sfere di alleanza. A questa base, dal 2010 progressivamente ristrutturata e aperta alle visite di un pubblico interessato a scoprire gli aspetti più segreti di un conflitto che si è combattuto per quasi mezzo secolo, è stato dato il nome suggestivo di Base Tuono (cfr. www.basetuono.it/ index.html).

Al volume che ne vuole illustrare le caratteristiche e le ragioni, e per certi versi le modificazioni nel tempo, è stato assegnato il titolo di Cieli fiammeggianti (Blazing skies), al tempo parola d'ordine in codice lanciata per i periodici controlli di funzionalità del sistema di sorveglianza stesso: una parola d'ordine forse attraente, oggi, e al tempo stesso rassicurante, però, preferita a quella di Launch missile, che pure sarebbe stata appropriata e significativa, perché era quella che avrebbe preceduto il lancio dei missili con testate convenzionali e nucleari che queste basi conservavano. Come a dire che, già nel titolo, di questi straordinari e temibili strumenti di guerra, si è preferito dare un'immagine difensiva piuttosto che offensiva: può sembrare una piccola sfumatura, ma forse non lo è.

Il volume è articolato in nove capitoli e sostanzialmente in tre parti. La prima, la più lunga e ambiziosa, vorrebbe dare al lettore un quadro generale della Guerra 
fredda e dell'evoluzione delle strategie militari che da parte occidentale l'hanno accompagnata. Una seconda introduce il lettore agli elementi di base della storia della missilistica, dei Nike e degli Hercules e dei reparti italiani dell'aeronautica che se ne sono occupati. La terza descrive com'era stata istituita Base Tuono, come era stata utilizzata, anche con testimoniane fotografiche o racconti di chi ne ha fatto parte. Come si capisce, il volume non è frutto di una ricerca archivistica originale, ma mette certamente a frutto le tante conoscenze tecniche degli animatori e degli allestitori della odierna Base Tuono: conoscenze certamente superiori alla media, molto forti sul dato tecnico. In questo senso, bene ha fatto il Comune di Folgaria a sostenere la pubblicazione, di modo che ai visitatori attuali di Base Tuono possa rimanere in mano una documentazione, peraltro riccamente illustrata.

Quindi bene ha fatto, a fini turistici, il Comune nel decidere di riottenere i terreni occupati dalla vecchia base, una parte dei quali è stata privatizzata (a favore di una compagnia di impianti di risalita) e l'altra, più piccola, è stata assegnata a Base Tuono. Altrettanto bene ha fatto l'Aeronautica a sostenere il progetto, perché sia ricordato quanto le forze armate del tempo (non solo l'Aeronautica: si pensi all'Esercito sulla soglia di Gorizia, o alle sue mine nucleari lungo il confine di terra, o alla Marina, e al suo coinvolgimento nella pianificazione della guerra navale del Mediterraneo) sono state parte attiva della Guerra fredda. Inoltre, ancora, bene ha fatto la Provincia autonoma di Trento (di rango regionale, si ricordi) nel sostenere il progetto, al fine di garantire uno spessore culturale e un impianto democratico e aggiornato alle attività di Base Tuono, che altrimenti avrebbe rischiato di essere lasciato al volontarismo di un gruppo, benemerito, di appassionati.

Va tutto bene, quindi? Non tutto, ma c'è la possibilità — se c'è la volontà — di rimediare ai problemi.

Se si voleva dare ai visitatori una guida aggiornata e seria alle tematiche sol- levate da Base Tuono, dalla Guerra fredda, dal coinvolgimento attivo in essa delle forze armate nazionali, del ruolo (importante ma non esclusivo) dell'arma nucleare, le istituzioni avrebbero fatto bene a coinvolgere anche gli studiosi. Che forse non sono molti, ma che ci sono. Nonostante le due pagine e mezzo di bibliografia poste a corredo del volume, stupisce che non siano nemmeno menzionati (forse non conosciuti), per esempio, il fondamentale studio di Leopoldo Nuti (La sfida nucleare, 2007) sulle relazioni diplomatiche italo-statunitensi alla base dell'assegnazione all'Italia di quelle testate nucleari, o se ci è permesso - il non meno fondamentale volume Le armi della Repubblica (2009) che con la quarantina dei suoi autori e le sue quasi 900 pagine rappresenta la più ampia introduzione alla politica militare dei decenni della Repubblica (assieme alla precedente Storia militare della Repubblica, di Ilari, 1994). Forse, anche all'assenza della consultazione di questi studi - e al coinvolgimento di questi studiosi, di vario orientamento - si devono alcune debolezze, e qualche volta errori, del volume. Forse, se fossero stati coinvolti, questi esperti avrebbero evitato di presentare irenicamente i Nike e gli Hercules come solo mezzi di difesa, cosa che non erano; di saltare il collegamento tutto nazionale fra le grandi, globali, strategie della Nato e le vicende, locali, della Base Tuono (ignorando il quale si ha l'idea che tutto fosse tecnico e inevitabile, quasi non ci fossero state scelte politiche); di eludere l'ampia storiografia internazionale, assai qualificata, ormai disponibile tanto sulla vita delle basi straniere nei territori nazionali della Guerra fredda, quanto sulla storia più in generale delle basi aeronautiche e missilistiche nazionali (l'assenza della comparazione impedisce di cogliere quanto quello che viene narrato di Base Tuono sia specifico e quanto invece consueto in questo tipo di basi). Soprattutto, se il mondo degli studi fosse stato coinvolto, non si sarebbe persa l'occasione di valorizzare di più di quanto si sia fatto in queste pa- 
gine il contributo dei tanti militari italiani che ci sono passati: la storia orale delle testimonianze di vita, talora, dice molto (si veda l'opera di Gianni Tomao e del sito Guardiano silenzioso: http://nikemissile. altervista.org/presentazione.html). Ovviamente, in attesa di poter consultare la documentazione archivistica nazionale e internazionale.

Il volume si avvantaggia della premessa di Giuseppe Ferrandi, direttore del Museo storico del Trentino, e della prefazione (e dell'appoggio) del generale dell'Aeronautica Basilio Di Martino, noto storico militare, conoscitore di Folgaria. Siamo certi che questi esperti e queste istituzioni potranno aiutare Base Tuono, affiancandole il sostegno degli studiosi e della ricerca, così come sapranno garantire che una delle pochissime istituzioni nate a memoria pubblica della rilevanza del coinvolgimento italiano nella Guerra fredda non rimanga una, pur benemerita, iniziativa locale di, pur benemeriti, volontari della memoria, affinché possano farla crescere e farla assurgere, come merita, al posto che le spetta fra le istituzioni della memoria nazionale.

Nicola Labanca

Soldati. Quando la storia si racconta con le caserme, catalogo dell'esposizione omonima, Gorizia, 30 ottobre 2015-28 febbraio 2016, Gorizia, Fondazione Cassa di risparmio di Gorizia, 2015, pp. 131, sip.

È stato una grande merito della Fondazione Cassa di risparmio di Gorizia, aver voluto organizzare fra il 2015 e il 2016 una bella mostra fotografica sulle caserme di Gorizia. D'altro canto, per una città che ha vissuto per mezzo secolo immediatamente alle spalle del confine italiano, cioè occidentale, con il mondo del socialismo reale, come dimenticare che il territorio di quell'area fu enormemente militarizzato dalla Guerra fredda? Peraltro, elevandosi appena un poco dal localismo municipale, non era chiamata tutta quell'area del basso Friuli appunto la "soglia di
Gorizia"? E non avrebbe potuto essere più o meno la "soglia di Gorizia" il territorio in cui - nei piani difensivi della Nato - forze avanzanti o da est (Jugoslavia) o da nord (Brennero) avrebbero dovuto essere contrastate dalle forze armate italiane e dai supporti dell'Alleanza? E non sarebbe quindi stato questo territorio esposto all'alea di una guerra devastante, non solo convenzionale ma nucleare, momento locale di quello che sarebbe stato a quel punto lo scontro globale della Guerra fredda? Proprio avendo in mente questo scenario globale, lo storico non può non plaudere all'iniziativa della Fondazione che, attraverso un aspetto apparentemente parziale quale la ricostruzione della storia delle caserme militari insediate sul territorio locale, avrebbe potuto preludere a una riconsiderazione del più generale ed eccezionale processo di militarizzazione dei territori di confine. Con ciò anche contribuendo al ritorno di memoria e di attenzione sugli aspetti militari di un'era — quella della Guerra fredda - sempre più spesso dimenticati, o banalizzati, o ridimensionati, e che invece costituivano l'ossatura di quel periodo storico.

Per fare tutto questo, però, erano - sarebbero state - necessarie, le competenze scientifiche e accademiche più raffinate: che, pure non numerose, erano disponibili: si pensi, solo per fare un esempio, al saggio di Daniele Ceschin, I "paesi-caserma”. Il Friuli ai tempi della naja, proprio a questo dedicato, ed edito nel volume Le armi della Repubblica (Torino, Utet, 2009, vol. V di Gli italiani in guerra), o alla bella ricerca di Domenico Rizzo, Vita di caserma: autorità e relazioni nell'esercito italiano del secondo dopoguerra (2012). Inoltre, la mostra avrebbe potuto interagire più strettamente con alcuni dei progetti che la regione Friuli Venezia Giulia ha finanziato, fra cui si ricorda quello intitolato "Un Paese di primule e caserme" (2008, e poi 2011-2014).

L'organizzazione dell'esposizione è invece stata affidata a "Isonzo. Gruppo di ricerca storica" (www.isonzo-grs.it/) che 
si autodefinisce "associazione culturale apolitica e apartitica”, nata a Gorizia nel 2006, che vede attivi — fra gli altri — Bruno Pascoli e Sergio Chersovani. Tra le produzioni di "Isonzo" si ricordano $\mathrm{Ju}$ lia: alpini a Gorizia (2016), Uno Stato in uniforme: la società goriziana e l'impero asburgico alla vigilia della grande guerra (2014), Ultime salve della duplice monarchia: artiglieri, cannoni e bombarde austro-ungariche (2011), La testa di ponte di Gorizia (1915 -1916). Testimonianze da un album di guerra, vicende della $58^{a}$ Divisione austro-ungarica e del suo comandante, il generale Erwin von Zeidler (2010), Dal Podgora a Gorizia. I Carabinieri e il $13^{\circ}$ Reggimento Carabinieri nella storia della Città (2010), Gira, gira l'elica, romba il motor... Aviazione ed aviatori a Gorizia 1909-1962 (2009), L'apocalisse di San Giorgio: Lucinico e dintorni 1915-1918 (2008), Il focolare di legno - Profuganze isontine nei campi di raccolta dell'impero, 1915-1917 (2008), 1918: dal Piave a Gorizia nel $90^{\circ}$ dalla fine della Grande guerra (2008), Lucinico 1915-1917 (2006), Il Castello di Gorizia nella Grande Guerra (2008). Per tali ragioni, la mostra e il catalogo che ne rimane e che qui di discute hanno inevitabilmente avuto un carattere molto locale, ricchi di documentazione anche importante, ma in cui in generale si perde un po' il quadro generale. E non è un caso se nella bibliografia finale i saggi di Ceschin e Rizzo sono ignorati: cioè, pensiamo, non conosciuti: ed è un peccato.

Ciò detto, gli aspetti di interesse sono stati numerosi. In primo luogo, una prospettiva storica "lunga". Partendo dalla Gorizia ottocentesca e austriaca, il catalogo dimostra come la militarizzazione di un territorio di confine ha una storia assai risalente nel tempo. Anche la documentazione, attraverso fotografie e documenti, della militarizzazione della Gorizia immediatamente successiva al 1919 e poi fascista offre aspetti di sicuro interesse. E poi c'è la Gorizia del secondo dopoguerra, con il suo all'inizio incerto status, poi deter- minato dal Trattato di pace del 1947, che vede compresenze militari italiane e alleate, di fronte a una popolazione locale popolazione italiana e slava, non necessariamente divisa lungo crinali etnici, bensì politici — che certo guardò a questa nuova rimilitarizzazione con sguardi assai diversificati. L'uso della prospettiva "lunga" permette anche di vedere come gli stessi edifici siano stati utilizzati e riutilizzati nel corso del tempo, da sistemi e regimi politici diversi, e come col passare dei decenni le strutture militari e i regimi politici abbiano provveduto a creare/demolire/ ricreare edifici, installazioni, caserme, rimodellando il territorio a proprio scopo. Dando origine, come è evidente soprattutto nelle regioni del Friuli e del Veneto (e per certi altri versi in Sardegna) a una consistente accumulazione di beni demaniali di origine militare oggi non più necessari alle forze armate, e di cui le società contemporanee devono decidere la conversione.

Se quindi non mancano i motivi di interesse, stupisce invece la colossale sottovalutazione del periodo della Guerra fredda. (Anche se, forse, potremmo dirla, come vedremo, un'opportunità). L'esposizione e il catalogo di Gorizia... quasi non parlano della soglia di Gorizia! La eccezionale militarizzazione del territorio di quei decenni, che ebbe tra l'altro com'è noto aspetti convenzionali ma anche nucleari (si pensi ai campi di mine atomiche rapidamente disinstallati alla fine della Guerra fredda), e che ha sollevato in più occasioni l'interesse dell'opinione pubblica (si veda http://inchieste.repubblica. it/it/repubblica/rep-it/2015/02/23/news/caserme_-_quadro_nazionale-105504735/), è nel catalogo risolta in poche pagine. In queste, peraltro, prevale il senso della pur bellissima immagine di copertina, relativa all'arrivo a Gorizia dei primi reparti militari italiani (carabinieri motociclisti) nel 1947: con la folla festante e plaudente e con il militare che bacia un bimbo in braccio a una donna. Cioè, in poche parole, prevale la propaganda. 
Si rileva questo non per dire che l'eccezionale militarizzazione delle caserme della soglia di Gorizia in tutti i decenni della Guerra fredda non conobbe anche momenti di pacifica e fruttuosa convivenza generale: si pensi, solo per fare un paio di esempi diversissimi fra loro, alla rete di pizzerie aperte nella zona per sostenere $\mathrm{i}$ bisogni alimentari di centinaia di migliaia di militari in libera uscita serale, nonché alle diversificate interazioni uomini-donne che per mezzo secolo si instaurarono nell'area. Lo si rileva solo per dimostrare che si tratta di una storia grande, importante, e sostanzialmente rimasta estranea alla mostra. Si tratta però di una storia che non può oggi essere ignorata, né dagli storici né dalle opinioni pubbliche né dalle pubbliche amministrazioni.

Il punto è che affrontarla vanno coinvolte le energie scientifiche più innovative a livello nazionale, e non solo gruppi di appassionati di storia locale. Va messa in pratica una nuova interdisciplinarità che colleghi non solo storici e architetti (è vero che nella mostra erano esposte una carta e un video del progetto architettonico "Un Paese di primule e caserme" e che poi si è tenuto sul tema un pubblico dibattito: ma poco altro). Peraltro invece un incrocio disciplinare sarebbe benefico per tutti, compreso il citato progetto — www.google.com/maps/d/viewer?ll=46 $.112276 \% 2 \mathrm{C} 13.150241 \& \mathrm{spn}=0.978071 \% 2 \mathrm{C}$ $1.316184 \& \mathrm{hl}=\mathrm{it} \& \mathrm{t}=\mathrm{h} \& \mathrm{msa}=0 \&$ source $=\mathrm{em}$ bed\&ie $=U T F 8 \&$ mid $=1 \mathrm{VjEn} 9 \mathrm{~A} 0 \mathrm{wFV} 7 \mathrm{eS} 7$ cNw9EvxIQhc00 - il cui database, a oggi, riporta per Gorizia un solo sito militare (www.primulecaserme.it/blog/?p=921), mentre l'esposizione goriziana ne ha messo in rilievo alcune decine... Inoltre andrebbe tenuto assieme tutto il dibattito nazionale sul riuso delle strutture militari, in larga parte 'scomode eredità' della Guerra fredda (solo per fare un esempio, si veda la sessione di un recente convegno di geografi tenutosi a Roma l'11 dicembre 2015). Insomma il tema era bello e importante. Sarebbe però auspicabile, con l'ottimismo della volontà, che le lacune dell'im- postazione dell'esposizione potessero dare vita a una seconda puntata, in cui - assieme alle energie locali - potessero operare strutture e competenze nazionali, e non solo di storici. Solo così, come accennavamo, un'occasione solo in parte colta potrebbe invece diventare il primo passo di una marcia virtuosa e positiva attorno ad un tema che è di rilevanza eccezionale (come peraltro ben colgono, nelle loro pagine introduttive al catalogo, sia il presidente della Fondazione Cassa di risparmio di Gorizia, sia il sindaco di Gorizia).

Nicola Labanca

\section{Resistenza/resistenze}

Seicentomila No. La Resistenza degli internati militari italiani, a cura dell'Archivio nazionale cinematografico della Resistenza e Associazione nazionali ex internati, sezione di Torino, Torino, Kaplan, 2014, pp. 239, sip.

Negli ultimi trentacinque anni gli studi e le ricerche sugli internati militari italiani (Imi), sono aumentati considerevolmente. All'interno di questo percorso di studi s'inserisce questo volume, che si presenta come un dizionario divulgativo sull'internamento italiano nei campi di prigionia tedeschi durante la Seconda guerra mondiale. La sua specificità sta proprio nel fatto di essere una sintesi precisa e accessibile a tutti di una vicenda che è stata a lungo ignorata e poi talora raccontata per lo più sotto un profilo specialistico. Allegato al volume si trova anche un Dvd-documentario con la riedizione del film Seicentomila No di Pier Milanese, realizzato nel 2008 dall'Archivio nazionale cinematografico della Resistenza, all'interno del quale le dirette testimonianze di alcuni reduci raccontano gli anni di internamento. Le testimonianze sono supportate dall'utilizzo di materiali cinematografici di repertorio, cinegiornali e filmati di propaganda. Buona appare nel documentario la correttezza e la 
pertinenza nell'uso delle fonti e dei documenti. Nel saggio iniziale, a firma di Bruno Maida (L'internamento militare tra storiografia e memoria pubblica, pp. 19-34), la vicenda degli Imi viene contestualizzata nelle dinamiche storico-politiche e nei processi psico-sociali causati dalla Seconda guerra mondiale e si fa anche il punto sulla storiografia sul tema e sulla sua ricezione nella memoria pubblica. Il saggio successivo di Franco Cravarezza (Una scelta per $i$ soldati italiani nel 1943-1945, pp. 35-69) si propone invece di analizzare alcuni aspetti del comportamento militare degli Imi, come, per esempio, la questione del "No" alla collaborazione con i tedeschi.

Dopo questi saggi, che svolgono per molti aspetti anche un ruolo introduttivo, Corrado Borsa e Cristian Pecchenino (Seicentomila No: compendio di una storia, pp. 73-198) entrano nel cuore della questione offrendo un racconto dettagliato della vicenda degli Imi, a partire dall'armistizio e fino al secondo dopoguerra. Questo saggio permette di avere un quadro chiaro delle vicende che portarono all'internamento dei soldati italiani, della dislocazione delle armate italiane sui vari fronti, dei meccanismi di disarmo e di cattura da parte dei tedeschi dalla notte dell'8 settembre. A questo registro narrativo seguono pagine che raccontano e problematizzano le condizioni di vita all'interno dei campi nazisti e le diverse scelte fatte dagli internati: aderire alla Repubblica sociale italiana o rimanere nei campi di prigionia. Condizioni di vita e scelte che variavano in base ai tempi, ai luoghi, ai rapporti che gli Imi riuscivano a costruire con i carcerieri, ma anche con i prigionieri di guerra di altre nazionalità e con gli stessi commilitoni italiani. La possibilità che l'Italia potesse rompere il patto di alleanza con la Germania, come documentato dai due autori, era tutt'altro che remota nella mente dei quadri militari e politici nazisti. Già dal maggio 1943, infatti, i piani di guerra nazisti prevedevano "le possibili contromisure in termini di disarmo e cattura delle truppe italiane e di oc- cupazione dei territori da esse presidiati" (p. 81). Disposizioni e piani che trovarono la loro realizzazione tra la notte dell'8 settembre e i giorni immediatamente successivi all'armistizio.

Gli autori sintetizzano bene il fatto per cui, se la prigionia di un numero così elevato di soldati poneva ai tedeschi problemi di gestione, organizzazione e trasporto nei campi nazisti da diverse aree geografiche del fronte, era pure evidente che, come lo stesso Goebbels ebbe a dire, l'internamento e la prigionia di tanti militari e civili rastrellati dal sistema nazista in tutta Europa divenne per l'economia di guerra tedesca un buon affare. Se le speranze della Repubblica sociale italiana erano quelle di trovare, attraverso il reclutamento tra gli Imi, soldati per il proprio esercito, per la Germania di Hitler divenne centrale la piena disponibilità invece di forza lavoro, in un momento impegnativo per l'industria tedesca, nella fase più critica della guerra totale. Fu questa, infatti, una delle ragioni che determinò il passaggio da prigionieri a internati militari e poi nell'autunno 1944 alla trasformazione dei soldati italiani in lavoratori civili. I soldati italiani fatti prigionieri dopo il disarmo e l'arresto venivano inviati in campi di smistamento, Dulag, per poi essere distribuiti, a seconda del loro grado militare, negli Oflag (gli ufficiali), negli Stalag o nei campi secondari (i soldati). La vita nei campi di prigionia, come viene ricostruita in queste pagine, fu dura a prescindere se gli internati fossero stati destinati negli Oflag o negli Stalag. D'altro canto, anche se gli ufficiali italiani "potevano essere privilegiati rispetto ai propri soldati", in confronto ai loro omologhi di altre nazionalità subivano condizioni di vita peggiori (p. 128). Ai militari italiani sostanzialmente venne riservato un trattamento peggiore rispetto a francesi e inglesi; migliore solo in confronto ai russi e ai polacchi che occupavano l'ultimo gradino gerarchia. Proprio in queste condizioni di vita, cui si aggiunsero quelle di un veloce deterioramento psicofisico, una percentuale non alta di soldati italiani maturò 
la scelta di aderire alla Repubblica sociale italiana, in cambio del ritorno in Italia o di condizioni di vita migliori. Mentre la maggior parte degli altri internati decise di portare avanti una resistenza mossa in un primo momento dal rifiuto della guerra e successivamente anche dal "bisogno di riconfermare e difendere la propria dignità di uomini e di soldati opponendo un rifiuto di tipo innanzitutto etico" (p. 129). La lunga resistenza degli internati militari nei campi di prigionia tedeschi non finì, per la maggior parte di loro, con la guerra nel 1945. Il loro ritorno a casa divenne lungo e per molti aspetti impossibile: "fino a diventare di quasi un anno per quanti si ritrovarono nella zona sovietica” (p. 193).

Ai traumi e alle umiliazioni subite dagli Imi nei campi nazisti si sommarono le difficoltà patite al rientro in Italia, negli anni del secondo dopoguerra caratterizzati dal dualismo ideologico tipico della Guerra fredda. Quei traumi e quelle umiliazioni divennero così difficili da raccontare. La storia e la memoria di quei fatti sembrava in quel particolare clima storico-politico non adatta ad essere raccontata e valorizzata e fu vittima, fino ad anni non molto lontani, di una lunga rimozione (come ricorda Claudio Sommaruga nell'appendice al libro, pp. 199-205). Una rimozione che lavori divulgativi come Seicentomila No di certo contribuiscono a combattere.

Giuseppe Ferraro

Marco Minardi, L'orizzonte del campo. Prigionia e fuga dal campo PG $49 \mathrm{di}$ Fontanellato 1943-1945, Fidenza, Mattioli 1885, 2015, pp. 135, euro 14.

La storia che Minardi ricostruisce, nella nuova e ampliata edizione di un volume edito vent'anni fa (1995, 100 pp., sul frontespizio: Comune di Fontanellato, Comitato provinciale di Parma per le celebrazioni del cinquantesimo anniversario della Resistenza e della Liberazione.), è il "ritaglio" di una vicenda ampia e articolata, anco- ra non sufficientemente indagata dalla storiografia nei suoi aspetti complessivi, e, al contempo, una storia a sé, dotata di caratteri specifici, unici nel suo genere.

La vicenda ampia è quella della prigionia in Italia, tra il 1941 e il 1943, di circa 80.000 soldati appartenenti allo schieramento anglostatunitense (ma tra i prigionieri c'erano, oltre statunitensi e britannici, anche indiani, ciprioti, australiani ecc. insomma tutto il Commonwealth), detenuti fino all'armistizio in decine di campi disseminati sul territorio nazionale, e poi protagonisti di un tentativo di "tutti a casa" (i territori liberati, la Svizzera), in realtà raramente riuscito. Quando ciò accadde, tuttavia, fu grazie al sostegno della popolazione italiana e - bene fa, Minardi, a sottolinearlo con forza - delle organizzazioni della Resistenza, che seppe impegnarsi anche in questa non secondaria attività.

La storia specifica, invece, è quella di uno di quei campi, il n. 49, situato a Fontanellato, piccolo comune del parmense. A Fontanellato furono detenuti per sei mesi (dalla fine di marzo all'8 settembre 1943) circa 700 soldati alleati anglostatunitensi (nel senso sopra detto), per lo più ufficiali, che da quel campo si allontanarono, "ordinatamente", il giorno successivo alla divulgazione dell'armistizio, grazie all'intelligenza, alla perspicacia e all'umanità degli ormai ex sorveglianti italiani, che ritennero fosse loro dovere (militare e politico, ma anche etico) evitare che quei soldati, non più nemici (ma a quel momento non alleati e neanche, ancora, cobelligeranti), finissero nelle mani dei reparti tedeschi. In questo, il caso di Fontanellato è un unicum, perché in altri campi le cose andarono in modo ben diverso, con $\mathrm{i}$ prigionieri costretti a restare rinchiusi fino all'arrivo dei nuovi detentori, o a scappare furtivamente, oppure ad approfittare dell'inatteso sbando dei loro sorveglianti, ma in questi casi destinati, con una maggiore probabilità, a essere catturati di nuovo e più rapidamente.

Merito della ricostruzione di Minardi è indubbiamente essere riuscito a mettere 
in luce questi aspetti, ma soprattutto l'essere stato in grado di seguire le tappe successive della storia di molti degli ufficiali già internati a Fontanellato, nei loro "percorsi" - non sempre, purtroppo, fortunati - verso la libertà, quei freedom trails, come loro stessi avrebbero avuto modo di definirli, che avrebbero irrimediabilmente segnato la memoria personale dei protagonisti e la conoscenza collettiva di quel determinato evento storico. Alla "libertà" (freedom) e ai suoi molteplici significati per gli ex prigionieri, Minardi dedica, in questa nuova edizione, un capitolo precedentemente intitolato "Il ritorno", in un cambiamento di denominazione carico di significato. Questo sforzo di ricerca e di ricostruzione - condotte attraverso molta memorialistica, perlopiù alleata, ma anche documentazione d'archivio proveniente dai National Archives di Kew, dall'Imperial War Museum di Londra (la maggiore novità, per quanto riguarda le fonti, di questa seconda edizione, sono proprio i diari dell'Iwm) e dai fondi dell'Istituto storico della Resistenza di Parma - non ha prodotto, tuttavia, solo la conoscenza di ciò che accadde agli ufficiali alleati, ma anche quella di ciò che la loro "avventura" significò per le comunità locali che, nella forma privata e individuale dell'impegno umanitario e civico, e in quella collettiva e organizzata dell'attività connessa alla lotta resistenziale, seppero apportare un contributo fondamentale, senza dubbio indispensabile, a quella che Roger Absalom ha definito la "grande evasione" (nella sua L'alleanza inattesa. Mondo contadino e prigionieri alleati in fuga in Italia (19431945), Bologna, Pendragon, 2011, traduzione in italiano dell'opera, dello stesso autore, A Strange Alliance. Aspects of Escape and Survival in Italy, 1943-45, Firenze, Olschki, 1991).

A parere di chi scrive, tuttavia, il pregio principale dello studio di Minardi risiede in un altro elemento, attinente a quanto detto poc'anzi, cioè al fatto che la storia complessiva della prigionia alleata in Italia - e, in generale, dell'esperien- za attiva della prigionia di guerra da parte degli italiani, non come detenuti ma come detentori — sia ancora oggi un capitolo non integralmente affrontato dalla ricostruzione storiografica. Grazie agli studi di Absalom e di altri, infatti, molto sappiamo oggi della fase bellica relativa al periodo successivo all'armistizio, che rappresenta anche la parte preponderante del racconto memorialistico dei prigionieri alleati, per ragioni comprensibili che rimandano alla difficoltà di narrare il tempo vuoto e sempre uguale della prigionia, soprattutto se paragonato a una fase che corrispose, invece, a quello che sarebbe diventato, per chi lo visse, un momento biografico centrale e determinante. L'inaspettata e inusuale "libertà" ottenuta con la fuga dal campo, il nascondimento in un paese sconosciuto e in parte ostile — data la presenza dei tedeschi e dei fascisti - la successiva storia di salvezza o nuova prigionia, sono, in questo senso, elementi già da tempo disponibili alla conoscenza collettiva.

Ciò che manca, ma che si sta man mano acquisendo, grazie ai lavori dello stesso Minardi — che può, a buon diritto, essere incluso tra coloro che hanno introdotto il tema in ambito nazionale - e di altri, è un approfondimento relativo alla fase prearmistiziale, cioè quella in cui i prigionieri alleati furono "ospiti coatti" del nostro paese. La storiografia italiana si muove sul tema ormai da più di vent'anni, producendo studi importanti su contesti locali, sebbene non sia ancora disponibile una ricostruzione complessiva di quello che fu un capitolo centrale dell'esperienza italiana della guerra. Condizioni di detenzione e trattamento, sistema complessivo dei campi, utilizzazione lavorativa della manodopera prigioniera, rapporti tra i diversi enti di gestione e tutela, contatti tra detentori civili e militari e uomini detenuti, e in generale aspetti politici, diplomatici, economici e strettamente militari relativi al ruolo dell'Italia detentrice, attendono ancora una sistematizzazione complessiva, che può e deve partire da lavori su contesti locali che siano approfonditi co- 
me quello di Minardi. Pur nella sua specificità, il caso di Fontanellato, così ben ricostruito, riassume in sé, dalla prospettiva del particolare, ognuno di questi elementi, ed è quindi base di partenza e utile pietra di paragone per un discorso più generale.

Isabella Insolvibile

Paolo Bianchi, Altre resistenze. Il campo di concentramento di Suzzara, Suzzara, Bottazzi, 2016, pp. 125, ill., euro 10.

Ricostruire una storia con un esiguo bagaglio di documenti a disposizione e il recupero di qualche testimonianza. Farlo per rimettere in ordine i tasselli di una "microstoria" incastonata nelle tragedie della Seconda guerra mondiale in Italia, nei mesi e negli anni più duri dell'occupazione nazista e della Rsi; pezzi di documentazione che s'incastrano e grazie ai quali, si auspica, possa essere riconsegnato alla memoria collettiva locale (e non solo) un luogo, o un non luogo nel senso antropologico del termine (come lo definisce l'autore), rimosso, ma una "memoria sepolta". È questa l'operazione in cui, con le già ricordate difficoltà, si cimenta Paolo Bianchi con questo volume, promosso dall'Istituto mantovano di storia contemporanea e dalle sezioni Anpi di Mantova, Suzzara e Motteggiana. Ne esce un prodotto solo apparentemente disorganico e sbrigativo, che invece non solo porta in sé i crismi propri di una ricerca, ma fornisce un inquadramento chiaro e una ricostruzione sufficientemente esaustiva della vicenda.

Del complesso universo concentrazionario creato dal fascismo e poi ereditato, in parte riutilizzato e soprattutto riadattato dai nazisti a partire dall'autunno 1943 non esistono troppi studi di carattere generale, se si escludono gli studi di Spartaco Capogreco, Brunello Mantelli, Costantino Di Sante e pochi altri. Decisamente più numerose, e ricorrenti, sono invece le analisi di singoli casi, fra i quali appunto questo del campo di Suzzara, cittadina pochi chilometri a sud del Po e snodo ferroviario lungo la linea che da Modena, quindi dal Polizei und Durchgangslager di Fossoli, conduce a Verona, al Brennero e quindi in Germania. La direttrice seguita da migliaia di italiani che, a partire dal settembre 1943, furono coinvolti nelle deportazioni.

Il campo di Suzzara ebbe una vita relativamente breve, dalla fine 1943 al termine dell'estate 1944, quando sono documentati gli ultimi ingressi stando alle fonti attualmente disponibili ed esaminate. Da quel momento in poi, in virtù degli sviluppi delle operazioni belliche e dell'intensificazione dei bombardamenti alleati sulle infrastrutture stradali e ferroviarie padane, Suzzara risulta avere (formalmente o informalmente) perso il ruolo proprio autonomo, divenendo nei fatti un distaccamento della struttura di Gonzaga e delle altre esistenti a Mantova e negli immediati dintorni; dalla fine del 1944 non se ne hanno più tracce.

L'ubicazione del campo ricalca le norme canoniche per questo tipo di istituti, previsti e applicati per strutture analoghe. La sua genesi e le successive vicissitudini rispecchiano invece le condizioni di urgenza nell'approntamento, l'adattamento alle progressivamente mutate esigenze dovute, innanzitutto, alla crescita esponenziale dei rastrellamenti, le conseguenze della sostanziale subalternità del fascismo repubblicano all'occupante nazista. Soprattutto grazie alle testimonianze (che occupano la parte centrale e più consistente del volume), emerge chiaramente come il campo di Suzzara, articolato fra gli spazi interni di un edificio scolastico, la Casa del Fascio e un ex macello, il tutto a due passi dalla ferrovia, abbia essenzialmente funzionato come luogo di smistamento e quindi relativamente breve permanenza dei prigionieri.

Formalmente sotto la giurisdizione delle autorità fasciste locali, che però, di fatto, obbedivano a istanze ed esigenze degli occupanti, con un corpo di guardia decisamente ristretto numericamente, da Suzzara presumibilmente transitarono alcune migliaia di persone. Le prime tracce ri- 
mandano ai militari italiani catturati dalla Wehrmacht dopo l'Armistizio, mentre il gruppo senza dubbio più consistente e documentato - e probabilmente soggetto a una permanenza leggermente più lunga — è costituito da renitenti alla leva e civili catturati, a prescindere dal reale o meno diretto coinvolgimento nella Resistenza, catturati nei massicci rastrellamenti nazifascisti sull'Appenino centro-settentrionale della primavera-estate 1944; basti, in proposito, considerare che soltanto a seguito delle operazioni "Wallenstein" transitano per Suzzara oltre 1600 rastrellati, destinati ai campi del Reich. Al di là di specifiche operazioni di rastrellamento, è stimabile in diverse centinaia anche il numero di civili, di varie classi di età, che vi hanno sostato prima della destinazione al lavoro coatto in Germania; fra questi non soltanto chi era caduto nelle frequenti retate di cattura di manodopera, ma anche chi aveva risposto ai bandi per il reclutamento di "volontari", per sfuggire ai quali l'unica alternativa era darsi alla macchia. Per via della vicinanza con Fossoli, è documentato il passaggio per Suzzara di ebrei sia italiani che stranieri. Questi, come noto, in virtù delle disposizioni emanate dalla Rsi a fine novembre 1943 dovevano essere capillarmente ricercati e raccolti in appositi campi provinciali, che a volte si incrociavano con le strutture create in precedenza per $\mathrm{i}$ prigionieri di guerra, in vista di un successivo trasferimento altrove. Suzzara fu appunto per alcuni di loro una tappa di breve sosta in coincidenza del concentramento a Fossoli, prima del trasporto più a nord.

A corredo della descrizione e dell'illustrazione del luogo e della necessariamente breve ricostruzione storiografica, dopo la citata parte dedicata alle testimonianze delle diverse tipologie di individui rinchiusi in questo campo, il volume di Bianchi propone - oltre a qualche riflessione sulle differenti reazioni alla condizione di prigionia - un'interessante appendice in cui vengono illustrati i caratteri di questa fase storica nel Mantovano e nelle aree immediatamente circostanti; vengo- no inoltre fornite tabelle riassuntive, brevi approfondimenti, indicazioni bibliografiche specifiche e documenti d'epoca. Anche in virtù di questo, lo studio "locale", ispirato dalla volontà di rendere noto un frammento significativo della memoria di un territorio circoscritto, mantiene la sua utilità, senza assumere i possibili difetti e limiti di uno studio dall'orizzonte troppo ristretto. È la storia stessa del campo a schiudere una storia non locale ma tendenzialmente globale, con il suo sguardo verso esperienze analoghe di altri campi, in altre parti d'Italia; un ulteriore, decisivo, passo potrebbe però essere garantito dall'accesso alle fonti tedesche, qui non utilizzate, e non dalle scarse fonti reperibili negli archivi italiani.

Tommaso Rossi

\section{Deportazioni}

Martin Baumeister, Amedeo Osti Guerrazzi, Claudio Procaccia (a cura di), 16 ottobre 1943. La deportazione degli ebrei romani tra storia e memoria, Roma, Istituto storico germanico di RomaViella, 2016, pp. 204, euro 24.

È ben noto che quella del 16 ottobre 1943 è stata la più tragica deportazione di ebrei avvenuta dall'Italia. Una foltissima pubblicistica sull'argomento ha avuto ampie ripercussioni sul piano mediatico, in Italia e all'estero, con numerosi articoli e indagini di giornalisti, oltre a una consistente produzione di narrazioni letterarie e cinematografiche. Nel loro insieme tutti questi interventi hanno contribuito ad affermare quell'evento cruento come un basilare luogo della memoria ebraica e italiana, benché da più parti si osservi polemicamente che le istituzioni italiane - in modo deresponsabilizzante - non hanno poi scelto proprio quella data di spiccato interesse nazionale per ricordare la Shoah con un Giorno della memoria, ma dal 2000 hanno preferito commemorare la liberazio- 
ne del campo di Auschwitz: la ricorrenza di un fatto accaduto lontano dall'Italia.

La grande abbondanza di materiali memorialistici sull'evento romano dell'ottobre 1943 ha inevitabilmente generato una spessa stratificazione di luoghi comuni, che solo da alcuni anni gli storici stanno cercando di sfrondare, per concentrare l'analisi dei fatti su dati accertati, anziché sull'immaginario creatosi intorno a quegli eventi. Promosso a Roma dall'Istituto storico germanico in stretta collaborazione con l'Archivio storico della Comunità ebraica, opera di alcuni dei maggiori studiosi specialisti della violenza nazifascista in Italia, ora questo volume è finalizzato, con buoni risultati, a fissare con rigore i dati obiettivi di quella tragedia e ad avviare simultaneamente un'altrettanto rigorosa analisi di come sia avvenuta - a opera delle più diverse soggettività - la sua elaborazione come luogo emblematico di varie memorie. Il libro costituisce il momento in cui gli storici si riappropriano di questo evento. Gli autori degli scritti sono i seguenti: Claudio Procaccia, Martin Baumeister, Sara Berger, Lutz Klinkhammer, Gabriele Rigano, Silvia Haia Antonucci, Mario Toscano, Hahle Badrnejad-Hahn, Damiano Garofalo e Amedeo Osti Guerrazzi. Si può dire che questo volume non porta alla luce nuove scoperte documentarie; ma certo porta a compimento una disamina particolarmente rigorosa di tutto il patrimonio archivistico sulla questione, con un utile lavoro di vaglio di molte notizie inesatte o congetture difficilmente sostenibili, che si erano andate accumulando in gran parte della pubblicistica prodotta sull'argomento, a cominciare dalle testimonianze dirette.

Quel 16 ottobre seguito all'armistizio con gli angloamericani, cioè poco più di un mese dopo che la Wehrmacht aveva occupato Roma, i tedeschi compirono nella città un'operazione che portò all'arresto di 1018 persone dei circa 11.333 ebrei che si stimavano residenti a Roma, che comunque ospitava anche numerosi altri ebrei profughi da paesi stranieri. Due persone morirono durante l'arresto e altre quattro si consegnarono per unirsi alle famiglie, sicché ad $\mathrm{Au}$ - schwitz furono deportati in 1020. Di loro la maggior parte fu uccisa all'arrivo; fra tutti i deportati tornarono a casa solo in sette. Negli otto mesi seguenti — prima che le truppe angloamericane entrassero in città - quasi altrettanti ebrei furono deportati da Roma, in larga parte dopo essere stati catturati dalle forze italiane obbedienti alla Repubblica sociale. Arrivare a stabilire questi dati con precisione ha richiesto un lavoro paziente e meticoloso, dal momento che nell'estrema confusione del periodo finale della guerra e del dopoguerra tali cifre risultavano alquanto incerte: la stessa documentazione della Polizia italiana portava a ritenere che la deportazione da Roma avesse coinvolto cinque migliaia di ebrei, che si supponevano catturati essenzialmente nel piccolo rione Campitelli. Le ricostruzioni emerse nei vari processi contro Herbert Kappler e altri nazisti spesso hanno contribuito alla diffusione di ulteriori ricostruzioni approssimative dei fatti, finendo per essere riprese anche nella produzione storiografica. A pesare sulla scarsa chiarezza sono soprattutto decenni di silenzi imbarazzati e di oblio volutamente messi in atto nel trattare la materia da parte di un paese come l'Italia fascista che aveva eretto l'antisemitismo a dottrina di regime. Si aggiunga, infine, il terribile trauma subito delle vittime e le strumentali deresponsabilizzazioni dei carnefici e dei loro differentemente stratificati collaboratori che hanno reso più difficile, anche per gli storici, una rigorosa determinazione dei fatti.

Un tema su cui i saggi di alcuni autori di questo volume accennano con qualche enfasi - senza tuttavia apportare nuove attestazioni documentarie a tali argomentazioni a parte le note deposizioni di Kappler davanti ai giudici nel dopoguerra — è l'ipotesi di una limitata collaborazione italiana alla Judenaktion del 16 ottobre. Tale richiamo viene lasciato nell'indeterminazione, ma pare riferito a una squadra della questura che ha contribuito alla logistica organizzativa della razzia, col predisporre per le SS gli elenchi e gli indirizzi delle famiglie da arrestare, dedotti dai registri ana- 
grafici da anni in uso in vari uffici pubblici. La dinamica dei fatti sinora documentabile tende a escludere altre significative partecipazioni attive - visibili o anche occulte - all'operazione da parte di elementi antisemiti italiani. Un indiscutibile potenziale antisemita era certamente presente nella città e in Italia, seppure negato a posteriori da una pervasiva faziosa tradizione che fino a tempi recenti ha vantato un preteso carattere bonario del fascismo e una spiccata tolleranza verso le diversità nella cultura nazionale. Tuttavia la scelta operativa di Dannecker e Kappler era stata di non informare in alcun modo gli elementi italiani, per evitare probabili fughe di notizie. È invece dalle settimane immediatamente successive alla Judenaktion che la caccia all'ebreo si è prevalentemente avvalsa di fondamentali apporti di delatori italiani o di arresti e retate da parte delle milizie neofasciste o della stessa polizia, con l'apporto degli apparati amministrativi della costituenda Repubblica sociale italiana.

Attente ricerche negli archivi militari e civili tedeschi hanno intanto permesso di smontare le versioni di comodo autoassolutorie con cui i diplomatici tedeschi a Roma e la stessa Wermacht avevano cercato di celare la loro sostanziale cooperazione alla razzia del 16 ottobre, attribuendone per intero la responsabilità alle SS. Sara Berger e Lutz Klinhammer mostrano bene come i vari apparati tedeschi presenti a Roma, pur recalcitranti a compromettersi, concorsero all'azione voluta da Himmler, rendendola possibile pur in un momento bellico poco opportuno, che richiedeva di privilegiare in tutti i modi la concentrazione delle forze militari al fronte, nell'estremo lembo dell'Italia meridionale, senza creare tensioni politiche o religiose a Roma. Le forze di Polizia e militari tedesche, raccogliticce e inesperte sulla viabilità urbana, vennero fornite in buona parte da unità dell'esercito. Col breve tempo e gli scarsi mezzi a disposizione per dispiegare l'operazione in tutti i quartieri di Roma, e inoltre per l'inopportunità di mostrare in città una plateale violenza efferata con l'u- so delle armi, Theodor Dannecker poté catturare un numero di ebrei parecchio inferiore alle aspettative iniziali, che prevedevano arresti almeno sei o sette volte più abbondanti. Accanto alle complesse ricerche sulla razzia dell'ottobre 1943, un'ampia sezione del volume presenta studi originali sulle varie modalità di elaborazione successiva della memoria relativa a quegli avvenimenti. A cominciare dalle difficili e dolorose scelte della Comunità ebraica per fare ricerche dei deportati, commemorare le persecuzioni subite ed elaborare in privato e in pubblico il proprio lutto, per proseguire con le cerimonie cittadine negli anniversari dell'evento, con partecipazioni non scontate delle diverse forze politiche. Si arrivano ad analizzare pure i testi letterari — di spicco quelli di Giacono Debenedetti, Umberto Saba ed Elsa Morante - e inoltre i numerosi film, sia documentari che di finzione, che trattano della razzia. Su questo stratificato sovrapporsi di testimonianze, variegate e spesso molto impressionistiche, non di rado si sono generate polemiche tra i diversi soggetti portatori delle memorie di una delle maggiori tragedie che hanno segnato l'Italia durante la Seconda guerra mondiale. Ricostruire con appropriate metodologie storiografiche come nel tempo quei ricordi si siano stratificati nella vita civile nazionale è quindi ora una impresa appropriata, per agevolare il riconoscimento e il superamento di persistenti rimozioni e distorsioni relative a quel tragico evento.

Marco Fincardi

Spaesamenti. Antifascismo, deportazioni e clero in provincia di Livorno, a cura dell'Istituto storico della Resistenza e della società contemporanea nella provincia di Livorno, Pisa, Ets, 2015, pp. 263, sip.

Il volume, uscito per il settantesimo anniversario della Liberazione, raccoglie i risultati di cinque ricerche che, attraverso l'approfondimento di alcune vicende riguardanti la provincia di Livorno consumatesi 
tra il 1943 e il 1945, arricchiscono la storia della Resistenza in Italia delle esperienze tragiche vissute non soltanto da personaggi noti della lotta al nazifascismo, ma anche e soprattutto dalla gente comune.

La documentazione, per la maggior parte conservata negli archivi toscani, raccolta e studiata con cura dagli autori dei saggi, è inedita. Originale in questo senso appare subito l'analisi da parte di Catia Sonetti del diario di un prigioniero militare italiano in Germania composto di dodici quaderni, scritti segretamente dal 23 settembre 1943 al 23 luglio 1945. Si tratta della testimonianza di un giovane contadino di poco più di vent'anni che ha così redatto una cronaca quotidiana della sua prigionia. In queste pagine si può leggere una sorta di Bildung di un uomo semplice, immerso nella cultura religiosa del tempo, che, internato filomonarchico e fedele al regime, tornò antifascista con una preferenza per la forma repubblicana. Stefano Gallo ha concentrato la sua analisi sulle reti antifasciste nel territorio costiero della provincia di Livorno, sulla loro costituzione, sviluppo e organizzazione, sulle difficoltà di intessere e mantenere relazioni e sull'importanza che esse rivestirono nell'ambito dell'attività resistenziale. In particolare, l'autore mette in luce la rete dei cristiano-sociali guidati da don Roberto Angeli, la cui azione politica e assistenziale ha tutte le caratteristiche della cosiddetta Resistenza civile. I suoi membri, infatti, erano persone esenti dal servizio militare, ovvero sacerdoti, ma anche uomini che non potevano più essere arruolati e soprattutto donne. L'attività di questo gruppo è richiamato anche nel saggio di Gianluca Della Maggiore dedicato alla Chiesa livornese e la guerra. Il vescovo di Livorno, Giovanni Piccioni, il cui atteggiamento sotto il fascismo è paragonabile a quello degli altri presuli italiani (deferenza verso il regime che aveva risolto la questione romana e che con il Concordato aveva riconosciuto il primato della religione cattolica), dopo il 25 luglio si allineò pubblicamente con il resto dell'episcopa- to toscano alle direttive contenute nella notificazione dell'arcivescovo di Firenze, Elia Dalla Costa, con la quale invitava clero e fedeli al rispetto delle "legittime autorità". Come rileva Della Maggiore, intorno a Piccioni poterono fiorire personalità e iniziative resistenziali che impongono di andare oltre i messaggi ufficiali per comprendere appieno il suo operato. Lo sfollamento cui furono costretti gli abitanti di Livorno dopo il bombardamento alleato del 28 maggio 1943 indusse il vescovo ad adattare il suo magistero alla nuova difficile situazione e a dar vita a una itinerante "pastorale per gli sfollati", confermando il ruolo centrale che la Chiesa cattolica ha avuto durante la guerra civile in Italia: un'istituzione sulla quale la popolazione poteva fare affidamento in luogo del potere politico. L'esodo verso le campagne limitrofe è al centro anche del saggio di Enrico Acciai che ha portato alla luce il caso della deportazione ad Auschwitz di tre famiglie ebree da Gabbro, una frazione di Rosignano Marittimo. Il 20 dicembre 1943 un gruppo di carabinieri e fascisti locali fece irruzione in una cascina, in cui avevano trovato rifugio alcuni ebrei in fuga dalla città. Vennero arrestate 17 persone tra cui bambini, donne e anziani che trovarono tutti la morte nel campo di sterminio in Polonia, tranne uno. Acciai ripercorre la storia di queste famiglie inserendo il caso di Gabbro nel più ampio contesto della guerra e della persecuzione degli ebrei, aggiornando la ancora poco approfondita storia della "caccia all'ebreo" nella penisola.

L'approccio microstorico è invece quello adottato da Matteo Caponi nella sua analisi del corteo popolare organizzato dai lavoratori dello stabilimento chimico belga Solvay a Rosignano all'indomani della caduta di Mussolini. La manifestazione del 27 luglio è rimasta impressa nel racconto pubblico della comunità rosignanese e nel ricordo delle generazioni più anziane, ma Caponi mette in luce anche il canone interpretativo che il suo ideatore, Enzo Fiorentini, allora leader di una cel- 
lula giovanile comunista clandestina, tese a promuovere nei suoi racconti degli anni Settanta e Novanta: l'episodio veniva presentato come la prova dell'antifascismo maturato dal popolo negli anni precedenti, finalmente libero di essere espresso. L'autore dimostra che il contesto nel quale la manifestazione venne evocata nel secondo dopoguerra influenzò in modo decisivo la narrazione degli eventi. Attraverso questo caso particolare affronta dunque due questioni storiografiche importanti: il problema del consenso popolare al fascismo e la effettiva presenza dell'antifascismo nella società italiana durante il ventennio.

Il filo rosso della Resistenza non armata lega le vicende analizzate in ciascun saggio, come ha notato Daniele Menozzi nell'introduzione, contribuendo a chiarire quale fu il comportamento della popolazione italiana tra il 1943 e il 1945, smentendo paradigmi storiografici non più sostenibili, come quello della ridotta partecipazione alla Resistenza. La promozione di uno studio puntuale, soprattutto a livello locale, del coinvolgimento a diverso titolo degli italiani nella lotta contro la dittatura, e la diffusione delle acquisizioni storiografiche anche presso il grande pubblico, potrebbero costituire un valido contributo per correggere percezioni e convinzioni sedimentate sul rapporto con il fascismo non solo degli italiani dell'epoca, ma anche di quelli di oggi.

\section{Raffaella Perin}

Bruno MaIDA, Il mestiere della memoria. Storia dell'Associazione nazionale ex deportati politici, 1945-2010, Verona, Ombre corte, 2014, pp. 256, euro 23.

Bruno Maida nel ripercorrere la storia dell'Aned dall'immediato dopoguerra al 2010, non rende soltanto onore agli uomini che si sono prodigati nel tenere viva la memoria della deportazione, bensì esamina l'intero processo con cui l'associazione ha affermato la propria identità e quella di tutti gli affiliati.
L'autore si avvale principalmente della documentazione conservata presso la Fondazione memoria della deportazione di Milano, oltre che del fondo Aned custodito dall'Istituto per la storia dell'età contemporanea di Sesto San Giovanni e conduce uno studio dell'associazione su scala nazionale, concentrandosi solo in parte sull'attività delle sedi locali, privandosi di una prospettiva che, a nostro giudizio, sarebbe stata utile per restituire un quadro più ricco e denso della vita dell'Aned.

La struttura della ricerca è lineare, ogni capitolo indaga i più significativi sviluppi dell'associazione. Grande attenzione è rivolta alla fase embrionale dell'Aned. Nell'immediato dopoguerra gli ex deportati sentirono il bisogno di ritrovarsi e di condividere le loro difficoltà nel reinserimento nella società, ma non riuscirono a tessere una rete comune. Occorre attendere, perciò, sino al 1957 per la costituzione dell'Associazione nazionale ex deportati politici nei campi nazisti (Andpcn), ben presto ribattezzata Aned. Pur aperta a chiunque avesse vissuto l'esperienza dei campi di concentramento nazisti e ai rispettivi familiari, l'ente rimarcava un connotato politico sin dal proprio nome, rivendicando un nesso con la Resistenza che soltanto "molti anni dopo gli storici avrebbero discusso e riconosciuto" (p. 85). Cominciava così il lungo e tortuoso percorso dell'Aned volto all'ottenimento di diritti fondamentali per gli ex deportati, al riconoscimento e alla valorizzazione della propria esperienza e alla possibilità di ritagliarsi uno spazio nell'opinione pubblica per esprimere la propria voce.

L'ottenimento di un indennizzo per tutti gli ex deportati stanziato dalla Germania federale nel 1961 rappresentò la prima significativa vittoria dell'Aned, sebbene l'autore non manchi di rimarcare limiti e criticità di quella misura. Un altro importante successo su cui inevitabilmente Maida si sofferma è l'acquisizione, nel 1980, di un assegno vitalizio di benemerenza, pari al minimo della pensione contributiva prevista dalla previdenza sociale, per le don- 
ne di età pari o superiore a cinquant'anni e per gli uomini di cinquantacinque o più anni che trascorsero un periodo nei campi di concentramento o nella Risiera di San Sabba.

L'autore dedica ampio spazio anche alla battaglia con cui l'Aned provò a inserire l'esperienza della deportazione nella memoria nazionale. Maida esamina con grande attenzione una serie di importanti iniziative condotte dall'associazione, tra cui la Mostra della deportazione del 1959 che attirò tra i 70.000 e gli 80.000 visitatori, ma che fu accompagnata da forti polemiche. Gli ex deportati, infatti, furono accusati di rinfocolare l'odio, ostacolando il delicato processo di pacificazione del $\mathrm{Pa}-$ ese. L'Aned, tuttavia, proseguì imperterrita. In tal senso, la realizzazione del Museo monumento al deportato politico e razziale a Carpi nell'ottobre 1973 rappresentò un altro importante successo. Nel frattempo, i vertici dell'Aned si dichiararono concordi nel concentrare i propri sforzi sulla storia: non bastava più che l'esperienza dei deportati rimanesse incisa sulle lapidi o venisse narrata nei pannelli delle mostre, occorreva che entrasse nei manuali di storia e, ancor prima, nel dibattito storiografico che l'aveva colpevolmente trascurata sino a quel momento. "Sostenere - scrive Maida - che prima degli anni Ottanta la storiografia sulla deportazione italiana nei Lager nazisti non esistesse, non costituisce un'esagerazione" (p. 216); fu l'Aned, dunque, a farsene promotrice. Se Un mondo fuori dal mondo. Indagine Doxa fra i reduci dai campi nazisti, apparso per i tipi della Nuova Italia nel 1970, fu un insuccesso con poco più di settanta copie vendute, i lavori condotti nel decennio successivo ebbero un impatto assai mag- giore. Il gruppo di ricerca torinese coordinato da Anna Bravo, Anna Maria Bruzzone, Federico Cereja e Brunello Mantelli raccolse più di 223 testimonianze di ex deportati nei campi di sterminio nazisti, residenti in Piemonte al momento della ricerca, e ideò il prezioso Archivio della deportazione piemontese. Seguirono poi, tra il 1986 e il 1992, una serie di importanti volumi che esplorarono il tema della deportazione da diversi punti di vista. Attorno al 1987, infine, alcuni soci dell'Aned rivolsero un appello affinché si costituisse un'istituzione che si assumesse "la responsabilità della gestione della storia della deportazione nei $\mathrm{Kz}$ nazisti in modo che, quando i superstiti non ci saranno più, qualcuno tenga vivo il ricordo di quel terribile evento" (p. 223). La realizzazione del progetto fu lenta, ma nel 1999 venne portata a termine con la nascita della Fondazione memoria della deportazione Biblioteca e Archivio Pina e Aldo Ravelli.

Il volume di Maida, complessivamente, ha il merito di mettere in luce che l'esperienza della deportazione più che essere rimasta oscurata dalla "tragedia spaventosa [...] del genocidio del popolo ebreo" (p. 243) come scrisse Luciano Violante nel 1998, fu piuttosto a lungo sottostimata e posta ai margini del dibattito pubblico dalle forze politiche e dalla storiografia. Peccato che il libro approfondisca quest'ultima questione solo a tratti, preferendo concentrarsi su come l'Aned abbia superato indenne i vari tornanti della storia, dal dopoguerra in avanti, mutando la propria fisonomia, ma riuscendo a rimanere "uno strumento di pedagogia democratica e costituzionale" di primaria importanza (p. 14).

Andrea Martini 